\title{
Glass-Water Interaction: Effect of High-Valence Cations on Glass Structure and Chemical Durability
}

J Hopf $^{1}$, SN Kerisit ${ }^{2}$, F Angeli ${ }^{3}$, T Charpentier ${ }^{4}$, JP Icenhower ${ }^{5}$, BP McGrail ${ }^{6}$, CF Windisch ${ }^{2}$, SD Burton ${ }^{7}$, and EM Pierce ${ }^{1 *}$

\section{Affiliations:}

${ }^{1}$ Environmental Sciences Division, Oak Ridge National Laboratory (USA);

${ }^{2}$ Physical Sciences Division, Pacific Northwest National Laboratory (USA);

$11{ }^{3}$ CEA DEN Laboratoire d'Étude du Comportement à Long Terme (France);

$12{ }^{4}$ NIMBE, CEA, CNRS, Université Paris-Saclay, CEA Saclay, (France);

$13{ }^{5}$ Carlsbad Programs Group, Sandia National Laboratories (USA);

$14{ }^{6}$ Energy Processes and Materials Division, Pacific Northwest National Laboratory (USA); and

$15{ }^{7}$ Environmental Molecular Sciences Laboratory, Pacific Northwest National Laboratory (USA)

\section{*Corresponding Author:}

18 Email: pierceem@ornl.gov,

19 Phone: (865) 574-9968

This manuscript has been authored by UT-Battelle, LLC under Contract No. DE-AC05-00OR22725 with the U.S. Department of Energy. The United States Government retains and the publisher, by accepting the article for publication, acknowledges that the United States Government retains a non-exclusive, paid-up, irrevocable, worldwide license to publish or reproduce the published form of this manuscript, or allow others to do so, for United States Government purposes. The Department of Energy will provide public access to these results of federally sponsored research in accordance with the DOE Public Access Plan (http://energy.gov/downloads/doe-publicaccess-plan). 
31 Borosilicate glass is a durable solid, but it dissolves when in contact with aqueous fluids. The dissolution 32 mechanism, which involves a variety of sequential reactions that occur at the solid-fluid interface, has 33 important implications for the corrosion resistance of industrial and nuclear waste glasses. In this study, spectroscopic measurements, dissolution experiments, and Monte Carlo simulations were performed to investigate the effect of high-valence cations (HVC) on the mechanisms of glass dissolution under dilute and near-saturated conditions. Raman and NMR spectroscopy were used to determine the structural changes that occur in glass, specifically network formers (e.g., Al, Si, and B), with the addition of the $\mathrm{HVC}$ element hafnium in the $\mathrm{Na}_{2} \mathrm{O}-\mathrm{Al}_{2} \mathrm{O}_{3}-\mathrm{B}_{2} \mathrm{O}_{3}-\mathrm{HfO}_{2}-\mathrm{SiO}_{2}$ system (e.g., $\mathrm{Na} /[\mathrm{Al}+\mathrm{B}]=1.0$ and $\mathrm{HfO}_{2} / \mathrm{SiO}_{2}$ from 0.0 to 0.42 ). Spectroscopic measurements revealed that increasing hafnium content decreases $\mathrm{N}_{4}$ (tetrahedral boron/total boron) and increases the amount of $\mathrm{Si}-\mathrm{O}-\mathrm{Hf}$ moieties in the glass. Results from

41 flow-through experiments conducted under dilute and near-saturated conditions show a decrease of 42 approximately $100 \times$ or more in the dissolution rate over the series from 0 to $20 \mathrm{~mol} \% \mathrm{HfO}_{2}$. Comparing 43 the average steady-state rates obtained under dilute conditions to the rates obtained for near-saturated 44 conditions reveals a divergence in the magnitude between the average steady state rates measured in these 45 different conditions. The reason for this divergence was investigated more thoroughly using Monte Carlo 46 simulations. Simulations indicate that the divergence in glass dissolution behavior under dilute and near47 saturated conditions result from the stronger binding of $\mathrm{Si}$ sites that deposit on the surface from the 48 influent when $\mathrm{Hf}$ is present in the glass. As a result, the residence time at the glass surface of these newly49 formed $\mathrm{Si}$ sites is longer in the presence of $\mathrm{Hf}$, which increases the density of anchor sites from which 50 altered layers with higher Si densities can form. These results illustrate the importance of understanding 51 solid-water/solid-fluid interactions by linking macroscopic reaction kinetics to nanometer scale interfacial 52 processes.

53 Key Words: solid-water reactions, borosilicate glass, high valence cations, Monte Carlo simulations, 54 glass corrosion, glass durability, solid state NMR 


\section{INTRODUCTION}

56 Reactions that occur at the solid-fluid interface have relevance to a range of areas with energy and

57 industrial applications (e.g., natural gas recovery, material fabrication and durability, battery research, and

58 various industrial chemical separation processes utilizing heterogeneous catalytic reactions). In a global

59 context, the importance of solid-water interfacial reactions is difficult to overstate. These interactions

60 control the composition of the world's fresh water (e.g., lakes, streams, rivers, etc.), soil development and

61 nutrient distribution, formation of certain ore and hydrocarbon deposits, and the geochemical cycling of

62 elements in the Earth's Critical Zone (e.g., near surface environment that determine the availability of

63 life-sustaining resources) (Brown and Calas, 2012; Herndon and Brantley, 2011; Herndon et al., 2011;

64 Hochella and White, 1990; Oelkers and Schott, 2009). Moreover, solid-water interfacial reactions also

65 impact the sequestration, release, transport, and transformation of pollutants and contaminants (Davis and

66 Kent, 1990; Liu et al., 2006; Zachara et al., 2004). Recently, multi-scale or hybrid models, which

67 capitalize on advancements in the understanding of solid-water interfacial reactions, have been used in an

68 attempt to better predict the geochemical evolution of natural and engineered systems (Steefel et al.,

69 2005; Steefel and Maher, 2009). However, knowledge gaps in the fundamental understanding of

70 solid-water reactions impede our ability to link macroscopic reaction kinetics to nanometer scale

71 interfacial processes. These knowledge gaps result in the inability to adequately and accurately describe a

72 variety of microscopic processes (e.g., absorption, ion diffusion, growth, dissolution, precipitation, and

73 interfacial redox reactions) that represent the underlying phenomena controlling element cycles and

74 transport in natural systems.

Interest in the immobilization and disposal of vitrified nuclear waste (nuclear waste glass) has

resulted in the application of multi-scale or hybrid models to forecast radionuclide release originating

77 from possible glass-water reactions (Bacon and Pierce, 2011; Bourcier, 1994; Bunker et al., 1986;

78 Cailleteau et al., 2008; Chick and Pederson, 1984; Frugier et al., 2005; Gin et al., 2013; Gin et al., 2001;

79 Grambow, 1985; Grambow and Müller, 2001; Icenhower et al., 2008; Jegou et al., 2000; Jollivet et al., 
2008; McGrail et al., 1997; McGrail et al., 2001; Pierce and Bacon, 2009, 2011; Pierce et al., 2014; Pierce et al., 2010; Pierce et al., 2008). Because of the critical role glass-water reactions play in the estimates of radionuclide release, an increase in the fundamental understanding of these processes is required to improve confidence in the long-term storage of vitrified nuclear waste in geologic systems (Gin, 2014; Gin et al., 2015; Grambow, 2006; Hellman et al., 2015; Putnis, 2015).

An important step in improving our ability to accurately forecast radionuclide release from corroding nuclear waste glass is to establish a link between the glass atomic-level structure and macroscopic dissolution behavior. In recent years, studies have placed emphasis on exploring this linkage in greater detail (Angeli et al., 2008; Arab et al., 2008; Bergeron et al., 2010; Cailleteau et al., 2008; Hopf and Pierce, 2014; Icenhower et al., 2008; Kerisit and Pierce, 2011, 2012; Pierce et al., 2010). For example, the study by Pierce et al. (2010), focused on determining the effects of varying the boron to aluminum ratio $(\mathrm{B} / \mathrm{Al})$ on the dissolution rate of aluminoborosilicate glasses along the nepheline to malinkoite join referred to as the NeB glass series. The experimental study by Pierce et al. (2010) concluded that the rupture of either $\mathrm{Al}-\mathrm{O}$ or $\mathrm{Si}-\mathrm{O}$ bonds was the rate-limiting step controlling the dissolution. This conclusion was refined using the Monte Carlo simulations conducted by Kerisit and Pierce (2011) which indicated that at low $\mathrm{B} / \mathrm{Al}$ ratios the rupture of both $\mathrm{Al}-\mathrm{O}-\mathrm{Si}$ and $\mathrm{Si}-\mathrm{O}-\mathrm{Si}$ linkages contributed to the dissolution rate, whereas, at high $\mathrm{B} / \mathrm{Al}$ ratios, the dissolution rate was independent of the rupture of $\mathrm{Al}-\mathrm{O}-\mathrm{Si}$ linkages and was controlled by the dissolution of surface silicon sites with one bond to the glass and by dissolution via detachment of clusters. Furthermore highvalence cations (HVC) (e.g., hafnium and zirconium), which can be inserted into a Si network in the presence of charge compensators, can have a significant impact on the atomic-level structure and macroscopic dissolution behavior of aluminoborosilicate glasses (Cormier et al., 2000; Galoisy et al., 1999; McKeown et al., 2000; McKeown et al., 1999).

The present work seeks to extend the previous results by evaluating the influence HVCs - such as hafnium and zirconium-have on the structure and dissolution rate of sodium aluminoborosilicate 

storage and/or disposal in a geologic repository because of its high thermal neutron capture cross section

107 ( 115 barn). Additionally, hafnium is also used as a chemical surrogate for tetravalent actinides, such as 108 plutonium. Lastly, the effect of HVCs, such as zirconium, on the chemical durability of 109 aluminoborosilicate glasses has been well documented (Bergeron et al., 2010; Cailleteau et al., 2008;

110 Cailleteau et al., 2011; Lobanova et al., 2002). Because of the structural and chemical similarities between 111 hafnium and zirconium, hafnium is expected to also exert a similar effect on the rate of $\mathrm{Si}-\mathrm{O}$ hydrolysis 112 when added to the glass composition. These structural and chemical similarities include similar octahedral 113 coordination moieties $\left(\left[\mathrm{ZrO}_{6}\right]^{2-}\right.$ and $\left.\left[\mathrm{HfO}_{6}\right]^{2-}\right)$ in borosilicate glass, with alkali or alkaline earth elements 114 serving as charge-compensators. In addition to similar coordination moieties, the average bond distance 115 for $\mathrm{Hf}-\mathrm{O}(2.08 \AA)$ is approximately $0.01 \AA$ smaller than $\mathrm{Zr}-\mathrm{O}(2.09 \AA)$ in borosilicate glasses 116 (Connelly et al., 2011b; Farges et al., 1991; Jollivet et al., 2013; Lopez et al., 2005); which is consistent 117 with the $0.01 \AA$ difference observed in the crystalline minerals hafnon $118(\mathrm{Hf}-\mathrm{O}=2.188 \AA)$ and zircon $(\mathrm{Zr}-\mathrm{O}=2.198 \AA)$ (Hazen and Finger, 1979; Speer and Cooper, 1982). 119 The reason for the structural similarities between hafnium and zirconium is thought to be related to the 120 similarities in ionic radii for $\mathrm{Hf}(\mathrm{IV})=0.85 \AA$ and $\mathrm{Zr}(\mathrm{IV})=0.86 \AA$ (Shannon, 1976). The present study 121 adds to the knowledge obtained for zirconium-bearing borosilicate glasses by studying the effect of 122 hafnium in the $\mathrm{Na}_{2} \mathrm{O}-\mathrm{Al}_{2} \mathrm{O}_{3}-\mathrm{B}_{2} \mathrm{O}_{3}-\mathrm{HfO}_{2}-\mathrm{SiO}_{2}$ system.

123 The main objective of this work is to quantify the effect $\mathrm{HfO}_{2}$ substitution has on glass durability 124 under dilute and near-saturated conditions with respect to amorphous silica. Additionally, we provide 125 insight into the structural changes that occur to the glass network as $\mathrm{HfO}_{2}$ content increases from 0 to $126 \quad 20 \mathrm{~mol} \%$. 


\section{EXPERIMENTAL DETAILS}

\subsection{Glass Chemistry, Material Preparation, Surface Area, and RMS roughness}

The glasses evaluated in this investigation were prepared according to the formula:

$$
(1-n) \mathrm{Na}_{2} \mathrm{O} \cdot \frac{1}{4}(1-n) \mathrm{Al}_{2} \mathrm{O}_{3} \cdot \frac{3}{4}(1-n) \mathrm{B}_{2} \mathrm{O}_{3} \cdot 5 n \mathrm{HfO}_{2} \cdot 3(1-n) \mathrm{SiO}_{2}
$$

where $0 \leq n \leq 0.2$.

A series of Hf-bearing glasses were batched in 100 gram quantities and prepared by mixing reagent grade chemicals $\left(\mathrm{Al}_{2} \mathrm{O}_{3}, \mathrm{Na}_{2} \mathrm{CO}_{3}, \mathrm{H}_{3} \mathrm{BO}_{3}, \mathrm{HfO}_{2}\right.$, and $\left.\mathrm{SiO}_{2}\right)$ together in a ceramic ball mill. The mixtures were melted at $1500^{\circ} \mathrm{C}$ for 1 hour using a $10 \%$ platinum- $90 \%$ rhodium $\left(\mathrm{Pt}_{10} \mathrm{Rh}_{90}\right)$ crucible and then quenched on a steel plate. The resulting glass was then ground and re-melted in a covered $\mathrm{Pt}_{10} \mathrm{Rh}_{90}$ crucible. After an additional hour at melt temperature, the melt was poured into a mold to yield bars with approximate dimensions of $1.5 \mathrm{~cm} \times 1.5 \mathrm{~cm} \times 3.8 \mathrm{~cm}$. The bars were then annealed for 2 hours in a box furnace at $570^{\circ} \mathrm{C}$. After the 2 hour anneal, the furnace was turned off and the bars were allowed to cool to ambient temperature overnight. Each glass was readily pourable and yielded a clear visibly homogenous glass. The target composition in weight percent and mole percent is provided in Table 1 and 2 , respectively. Electron microprobe data for $\mathrm{Al}, \mathrm{Hf}, \mathrm{Na}$, and $\mathrm{Si}$ with $\mathrm{O}$ obtained by stoichiometry and $\mathrm{B}$ obtained by difference of select samples confirmed that the target glass compositions are within $0.6 \mathrm{~mol} \%$ of the measured compositions (Davis et al., 2003; Zhao et al., 2000). The glass samples used were designed to have a $\mathrm{Na} /(\mathrm{Al}+\mathrm{B})=1.0$ and a $\mathrm{HfO}_{2} / \mathrm{SiO}_{2}$ molar ratio that ranges from 0.0 to 0.42 . A brief discussion of how these glasses compare to the $\mathrm{HfO}_{2}$ glasses evaluated by Davis et al. (2003) is provided in supplemental information (Fig. SI1).

Prior to conducting experiments, the melted glass bars were then used to cut $20 \mathrm{~mm} \times 20 \mathrm{~mm} \times 1 \mathrm{~mm}$ coupons. The coupon samples were then polished initially using 200 grit sandpaper samples and then with $\mathrm{CeO}_{2}(<1 \mu \mathrm{m})$ paste. The surface area $(S)$ of each sample was estimated by measuring the coupon dimensions using an electronic caliper and ranged from 0.98 to $1.22 \times 10^{-3} \mathrm{~m}^{2}$. The apparent glass density was also estimated by obtaining the mass of the specimen (ranged between 0.33 and 0.45 grams) and 
155 calculating the volume from the coupon dimensions. The density ranged from $\sim 2.8 \mathrm{~g} / \mathrm{cm}^{3}$ for HF- 1 to $156 \quad 3.0 \mathrm{~g} / \mathrm{cm}^{3}$ for HF-5. After preparation, each sample was stored in a sealed container containing a $\mathrm{CaSO}_{4}$ 157 desiccant.

The atomic force microscopy (AFM) surface profile images were collected on polished coupons using 159 a Bruker Multimode 8 AFM in tapping mode to evaluate the surface topography of each sample. The 160 HF-2 data discussed in the supplemental information are representative of all the glass coupons tested 161 (Fig. SI2). For the topography and roughness, multiple scans were taken at $10 \mu \mathrm{m} \times 10 \mu \mathrm{m}$. Roughness

162 calculations were performed with the Nanospcope Analysis software and the parameters RMS (root mean 163 square roughness, Sq) was determined after conducting a simple plane fit. No additional image processing 164 was performed on the results.

\subsection{Raman Spectroscopy}

Raman spectra were collected on glass powder and polished coupons, respectively. The Raman spectra were collected using a Horiba JY LabRAM HR (Edison, NJ, high resolution) Raman (confocal) microscope system. With a focal length of $0.8 \mathrm{~m}$ and dual gratings with groove density of 2400 grooves $/ \mathrm{mm}$ the instrument can achieve a nominal spectral resolution of about $1 \mathrm{~cm}^{-1}$. Excitation was provided by the $244 \mathrm{~nm}$ line of a Lexel 85-SHG frequency-doubled Ar ion laser (Fremont, CA) equipped with a non-linear BBO (beta barium borate) crystal. Laser power was $25 \mathrm{~mW}$ at the source and approximately $2 \mathrm{~mW}$ at the sample. A $40 \times \mathrm{UV}$-compatible microscope objective $(\mathrm{NA}=0.75)$ was used. The spectrometer pinhole was kept fairly large, at $400 \mu \mathrm{m}$, resulting in less-than-optimal depth and lateral resolution. However, laser throughput was improved with the larger pinhole, giving exceptionally high Raman intensities, in some cases tens-of-thousands of counts when collected with a relatively short exposure time (200 s). The spectra range was restricted to Raman shift above $450 \mathrm{~cm}^{-1}$. Measurements at lower frequencies were not possible because of the presence of a factory-installed edge filter for eliminating the exciting line. As a consequence, Raman bands associated with deformation modes, commonly observed below $500 \mathrm{~cm}^{-1}$, were not observable in this study. Windisch et al. (2011) provides a 

conventional and deep-UV Raman spectra on a range of glass compositions. The pore signal-to-noise in conventional Raman spectroscopy with visible light $(457.9 \mathrm{~nm}$ and $514.5 \mathrm{~nm})$ was the result of weak

183 Raman signals and excessive Rayleigh scattering and fluorescence arising from surface features. The

184 decision to select deep-UV to minimize the impact background noise resulted in a trade-off because of the 185 restricted spectral range. Therefore, the spectral analyses focus on the stretching modes, both network and 186 those involving non-bridging oxygen (NBO) atoms, which occur at higher frequencies.

A more detailed description of the curve fitting procedure is provided in Windisch et al. (2011).

188 Briefly, spectral analysis including curve fitting was performed using Thermo Scientific (Waltham, MA)

189 Grams/32 AI software. Grams/32 AI uses the Levenburg-Marquardt non-linear peak fitting method. It 190 was applied here using Gaussian peak functions and restricted to the $800-1200 \mathrm{~cm}^{-1}$ region of the 191 spectrum. Prior to curve fitting, a weak exponential baseline correction was used to remove the small amount of background that persists in this region even with deep-UV excitation.

\subsection{Magic Angle Spinning-Nuclear Magnetic Resonance spectroscopy}

194 Magic angle spinning nuclear magnetic resonance (MAS-NMR) spectroscopy was conducted on unreacted glass powder samples, $<75 \mu \mathrm{m}$ (e.g., $<200 \mathrm{mesh}$ ), to obtain information on glass structure and relate the effect structure exerts on glass dissolution. The local coordination geometry around the Al, B,

$197 \mathrm{Na}$, and $\mathrm{Si}$ atoms on four of the five glasses was investigated at room temperature by ${ }^{27} \mathrm{Al},{ }^{29} \mathrm{Si},{ }^{23} \mathrm{Na}$, and $198 \quad{ }^{11}$ B MAS-NMR.

199 The ${ }^{11} \mathrm{~B},{ }^{23} \mathrm{Na}$, and ${ }^{27} \mathrm{Al}$ MAS-NMR spectra were collected on a Bruker Avance II Spectrometer at a 200 magnetic field of $11.72 \mathrm{~T}(500 \mathrm{MHz})$ using a $4 \mathrm{~mm}$ (o.d.) Bruker CPMAS probe (spinning frequency $20114 \mathrm{kHz}$ ). All spectra were acquired using a single pulse excitation (SPE) with a short pulse length $(1 \mu \mathrm{s}$, 202 tip angle $15^{\circ}$ ) to obtain a quantitative measurement (homogeneous excitation of all sites with respect to 203 their quadrupolar coupling constant strength) and a recycle delay of $1 \mathrm{~s}$ for ${ }^{23} \mathrm{Na}$ and ${ }^{27} \mathrm{Al}$, and $2 \mathrm{~s}$ for ${ }^{11} \mathrm{~B}$. 204 Approximately, 4096 scans were collected for each sample. For ${ }^{11} \mathrm{~B}$, multiple-quantum magic-angle 
spinning (MQMAS) spectra optimized for $\mathrm{BO}_{3}$ and $\mathrm{BO}_{4}$ observation (2 spectra for each sample) were acquired as described in Angeli et al., (2010). A correction was applied for the contribution of the satellite transition (ST) spinning sidebands to the $\mathrm{BO}_{4}$ centerband in the ${ }^{11} \mathrm{~B}$ SPE MAS NMR spectra. We performed this correction by subtracting the ST spinning sideband (second order) from the spectrum centerband. As discussed in the Supplemental Information, this method is supported by the fact that all 210 spinning sidebands near the centerband have the same lineshape (Fig. SI3) and their variation in intensity 211 from second order to centerband can be neglected (Fig. SI4). This correction is displayed in Fig. SI5 and 212 typically amounts to a reduction of $\sim 2 \%$ of the $\mathrm{BO}_{4}$ population. Further analysis of the $\mathrm{BO}_{4}$ peak was 213 obtained by the TOP method (Massiot et al., 2006). Briefly, this approach consists of folding back all the 214 spinning sidebands into the centerband frequency range, but introducing their order in a second 215 dimension. By extracting columns at a given chemical shift the shape of its spinning sideband manifold is 216 revealed, which mostly reflects the quadrupolar NMR parameters. Angeli et al. (2010) demonstrated that 217 this type of analysis is critical in identifying the existence of at least two $\mathrm{BO}_{4}$ species and in the 218 applicability of the Gaussian Isotropic Model (GIM) (thus the existence of a finite quadrupolar interaction 219 with a non-zero asymmetry parameter). Those two sites are also evidence in the MQMAS spectra (as 220 discussed below). The ${ }^{11} \mathrm{~B}$ chemical shifts are referenced to an external sample of $1 \mathrm{M}$ boric acid solution 221 (19.6 ppm). A $1 \mathrm{M} \mathrm{AlCl}_{3}$ solution was used as external reference for ${ }^{27} \mathrm{Al} \mathrm{NMR} \mathrm{spectra} \mathrm{and}{ }^{23} \mathrm{Na}$ chemical 222 shifts was referenced to a $1 \mathrm{M} \mathrm{NaCl}$ solution. The ${ }^{29} \mathrm{Si} \mathrm{MAS}-\mathrm{NMR}$ spectra were acquired on a Bruker 223 Avance I spectrometer at a magnetic field of $7.02 \mathrm{~T}$ using a Bruker $4 \mathrm{~mm}$ (o.d.) Bruker CPMAS probe 224 (spinning frequency $12.5 \mathrm{kHz}$ ). A Carr-Purcell-Meiboom-Gill (CPMG) pulse sequence (Larsen and 225 Farnan, 2002) was used with a recycle delay of 20 s (no change in lineshape was observed for longer 226 recycle delay of $200 \mathrm{~s}, 800 \mathrm{~s}$, Fig. SI6 and Fig. SI7). The spectra are referenced to an external 227 tetrakistrimethylsilane (TKS) sample for which the highest intensity peak is situated at $-9.9 \mathrm{ppm}$ from that 228 of tetramethylsilane (TMS). 
All data were processed and fitted using in-house written software. Methods for fitting the spectra

230 have been detailed in (Angeli et al., 2010; Angeli et al., 2012). Briefly, the ${ }^{27} \mathrm{Al},{ }^{23} \mathrm{Na}$, and ${ }^{11} \mathrm{~B}$ lineshapes

231 were fit considering a distribution of the NMR parameters and corresponding fit parameters (i.e., isotropic

232 chemical shift $\left[\delta_{\text {iso }}\right]$, quadrupolar coupling constant $\left[C_{Q}\right]$, and quadrupolar asymmetry parameter $\left.[\eta \square]\right)$

233 represent the mean of those distributions (Angeli et al., 2010; Angeli et al., 2007; Angeli et al., 2012;

234 Quintas et al., 2007). For ${ }^{27} \mathrm{Al},{ }^{23} \mathrm{Na}$, and ${ }^{11} \mathrm{~B}\left(\mathrm{BO}_{4}\right.$ units only), this distribution was chosen as the product

235 between a Gaussian distribution for the isotropic chemical shift and the GIM for the quadrupolar

236 parameters (namely the $C_{Q}$ and $\eta_{\square}$ ). It is important to note that the GIM distribution yields a constant

237 mean value of 0.6 for $\eta_{\square}$ For $\mathrm{BO}_{3}$ units, the product of three Gaussian distributions was chosen, as

238 detailed in Angeli et al. (2010). All 1D spectra are displayed normalized to the same maximum height.

\subsection{Buffer Solutions}

240 The influent solutions used to control the $\mathrm{pH}$ during the dissolution experiments were prepared with $2410.05 \mathrm{M}$ tris hydroxymethyl aminomethane (THAM) buffer in $18 \mathrm{M} \Omega \cdot \mathrm{cm}$ deionized water (DIW). The

242 silicon concentration in the influent solution was varied from dilute to saturated for these experiments by

243 adding the appropriate amount of analytical grade silicic acid powder $\left(\mathrm{SiO}_{2} \cdot \mathrm{H}_{2} \mathrm{O}\right)$ to the THAM buffer

244 and heating the solution in a $40^{\circ} \mathrm{C}$ oven for no less than three days to facilitate complete dissolution of

$245 \mathrm{SiO}_{2} \cdot \mathrm{H}_{2} \mathrm{O}$. Upon complete dissolution each solution was removed from the oven, allowed to cool, and $\mathrm{pH}$

246 adjusted [target $\mathrm{pH}\left(23^{\circ} \mathrm{C}\right)=9.0$ ] with aliquots of $15.8 \mathrm{M} \mathrm{HNO}_{3}$ or $1 \mathrm{M} \mathrm{LiOH}$. Prior to $\mathrm{pH}$-adjusting the

247 influent solutions, the $\mathrm{pH}$ probe was calibrated with National Bureau of Standards (NBS) buffers

$248\left(\mathrm{pH}=7.00,10.00\right.$, and 12.00 at $\left.23^{\circ} \mathrm{C}\right)$. The precision of the $\mathrm{pH}$ measurement was $\pm 0.1 \mathrm{pH}$ units. Based on

249 the results from calculations with the geochemical code EQ3NR [version 7.2b (Helgeson et al., 1978;

250 Johnson et al., 1992; Wolery, 1992)] the amount of Si added was altered from dilute to near-saturated

251 with respect to amorphous silica $\left[\mathrm{SiO}_{2}(\mathrm{am})\right]$. It is important to note that the solubility behavior of

$252 \mathrm{SiO}_{2}(\mathrm{am})$ changes with experimental conditions, therefore, the target amount of $\mathrm{Si}$ added to the buffer

253 solution was calculated for the experimental temperature of $23^{\circ} \mathrm{C}$, resulting in a Si solution concentration 
of $60 \mathrm{ppm}$. Although a $60 \mathrm{ppm} \mathrm{Si}$ solution is saturated at room temperature, we did not observe precipitation of silica in the influent or effluent solutions during the course of the experiments. Additionally, for Si saturated experiments conducted as a function of $\mathrm{pH}$, the solution $\mathrm{pH}$ was adjusted to the target values, $\mathrm{pH}\left(23^{\circ} \mathrm{C}\right)=8.0$ and 9.0 , using aliquots of $15.8 \mathrm{M} \mathrm{HNO}_{3}$ or $1 \mathrm{M} \mathrm{LiOH}$.

The $\mathrm{pH}$ of the influent and a select number of effluent solutions were monitored over the duration of

the experiments. Concentrations of $\mathrm{Al}, \mathrm{B}, \mathrm{Na}$, and $\mathrm{Si}$ in the influent and effluent solution samples were

260 determined with inductively coupled plasma-optical emission spectroscopy (ICP-OES). The average

261 background concentration, based on analysis of the influent solution and three blank solutions, ranged

262 from 10 to $30 \mu \mathrm{g} / \mathrm{L}$ for $\mathrm{Al}$, from 10 to $50 \mu \mathrm{g} / \mathrm{L}$ for $\mathrm{B}$, and from 100 to $500 \mu \mathrm{g} / \mathrm{L}$ for $\mathrm{Na}$ in experiments 263 conducted under diluted and near-saturated conditions. The average silica background concentration 264 varies from $1 \mathrm{mg} / \mathrm{L}$ for experiments conducted under dilute conditions to $88 \mathrm{mg} / \mathrm{L}$ for experiments 265 conducted under near-saturated conditions. Typically, background concentrations of elements are below 266 the sample estimated quantification limit (EQL). The sample EQL is determined by multiplying the 267 sample dilution factor by the lowest calibration standard that can be determined reproducibly during an 268 analytical run within $10 \%$. Before analysis, aliquots of the influent and effluent solutions were acidified 269 with ultra-high-purity concentrated $\mathrm{HNO}_{3}$.

\subsection{Single-Pass Flow-Through (SPFT) System and Effluent Solution Analysis}

271 For dilute solutions, the dissolution experiments were conducted at the forward or maximum 272 dissolution rate with the single-pass flow-through (SPFT) apparatus (Fig. 1). For consistency, the 273 solutions containing dissolved Si were carried out under the same forward rate conditions (i.e., similar 274 ratio of the flow rate to surface area $[q / S]$ conditions) as the dilute solutions. The SPFT system and the 275 techniques used to calculate the dissolution rate has been extensively described by others (Icenhower et 276 al., 2008; Icenhower et al., 2006; McGrail et al., 1997; Pierce et al., 2005; Pierce et al., 2008; Wellman et 277 al., 2006). To limit duplication, the reader should refer to the aforementioned references, as well as the 278 references contained therein for more details on the SPFT system. 
All SPFT experiments were conducted in a constant temperature oven $\left( \pm 2^{\circ} \mathrm{C}\right)$ at $23^{\circ} \mathrm{C}$ and at flow rates ranging from 2 to $20 \mathrm{~mL} \mathrm{~d}^{-1}$ ( $\sim 0.03$ to 0.25 reactor volumes per day). The solution temperature 281 inside of a blank reactor was measured with an in-situ thermocouple. The flow rate was determined by 282 weighing the volume of solution collected at each sampling time (i.e., gravimetrically) and variations 283 were typically less than 5\%. Once constant conditions (i.e., buffers, flow rates, temperature, etc.) were 284 established, the pre-weighed glass coupons were placed into a test vessel. Experiments were run until 285 steady-state effluent solution chemistries prevailed, which typically occurred after 3 to 8 reactor volumes.

286 The abbreviations selected to describe all of the glass samples and dissolution experiments are: HF-1 to 287 HF-5 corresponds to the 5 glass samples used with increasing hafnium concentration (untreated), D and S 288 are used for the dissolution experiments conducted under diluted conditions and near-saturated conditions, respectively (e.g. HF-4D and HF-4S refers to experiments conducted with $15 \%$ hafnium glass sample under diluted and saturated conditions, respectively).

\subsection{Quantification of Dissolution Rates}

Dissolution rates, based on steady-state concentrations of elements in the effluent, are normalized to the mass fraction of the element present in the sample by the following formula:

$$
r_{i}=\frac{\left(C_{i}-\bar{C}_{i, b}\right) q}{f_{i} S}
$$

where $r_{i}$ is the normalized glass dissolution rate based on the release of a particular element, $i,\left[\mathrm{~g} /\left(\mathrm{m}^{2} \cdot \mathrm{d}\right)\right]$, concentration of the element of interest $\left(\mathrm{g} / \mathrm{m}^{3}\right), q$ is the flow rate $\left(\mathrm{m}^{3} / \mathrm{s}\right), f_{i}$ is the mass fraction of the 
their respective detection threshold. In cases where the analyte is below the detection threshold, the background concentration of the element is set at the value of the detection threshold.

Determining the experimental uncertainty of the dissolution rate takes into account uncertainties of each parameter in Eqn. (2). For uncorrelated random errors, the standard deviation of a function $f\left(x_{1}, x_{2}, \ldots x_{n}\right)$ is given by:

$$
\sigma_{f}=\sqrt{\sum_{i=1}^{n}\left(\frac{\partial f}{\partial x_{i}}\right)^{2} \sigma_{i}^{2}}
$$

where $\sigma_{f}$ is the standard deviation of the function $f ., x_{i}$ is the parameter $i$, and $\sigma_{i}$ is the standard deviation

$$
\hat{\sigma}_{r_{i}}=\sqrt{\frac{\left(\hat{\sigma}_{C_{i}} C_{i}\right)^{2}+\left(\hat{\sigma}_{\bar{C}_{i, b}} \bar{C}_{i, b}\right)^{2}}{\left(C_{i}-\bar{C}_{i, b}\right)^{2}}+\hat{\sigma}_{q}^{2}+\hat{\sigma}_{f_{i}}^{2}+\hat{\sigma}_{S}^{2}},
$$

313 errors assigned to the parameters in Eqn. (4), in addition to the practice of substituting detection threshold

314 values for situations where the sample results were below the background concentrations because of

315 instrument limitations, results in typical $2 \sigma$ uncertainties of approximately $\pm 30 \%$ for SPFT-measured

316 dissolution rates (or $\pm 0.2 \log$ units when reported as $\log _{10}$ rates). To ensure the SPFT system yielded

317 reproducible results replicates of select experiments were conducted and a comparison of these results

318 indicated a deviation between replicates to $b e<30 \%$.

\subsection{Computational Methods}

320 All the calculations reported in this work were carried out with a parallel Monte Carlo computer 321 program developed and implemented for the purposes of this work. The Monte Carlo model is based on 322 the glass dissolution model of Devreux, Barboux, and co-workers (Devreux et al., 2001; Devreux et al., 323 2004; Ledieu et al., 2006; Lobanova et al., 2001). The Monte Carlo model is only briefly described here 
324 and the reader is referred to our previous publications (Kerisit and Pierce, 2011, 2012; Kerisit et al., 2015;

325 Kerisit et al., 2013) for more details.

In the MC model, the glass framework is mapped onto a cubic lattice wherein each lattice site represents a network-former cation (e.g. $\mathrm{Si}$ or $\mathrm{B}$ ) and its first oxygen coordination shell and network-modifier cations (e.g. $\mathrm{Na}$ ) are placed in interstitial positions. Two connections are removed at each lattice site to represent the fourfold connectivity of the network-former cations. Four elements were considered in the simulations carried out in this work: boron, silicon, sodium, and hafnium. Boron sites

331 dissolve instantaneously once in contact with the aqueous solution and are considered fully soluble.

332 Silicon sites with one, two, or three connections to silicon nearest neighbors dissolve with probabilities $333 w_{1}, w_{2}$, and $w_{3}$, respectively. In addition, silicon can deposit back at surface sites with probability $334 w_{\mathrm{r}}=w_{\mathrm{c}-\mathrm{Si}} c_{\mathrm{Si}}$ where $w_{\mathrm{c}-\mathrm{Si}}$ is the silicon condensation probability and $c_{\mathrm{Si}}$ is the silicon concentration in the 335 aqueous solution. Hafnium was added in octahedral sites, following the implementation of 336 Arab et al. (2008) for octahedral cations. Hafnium sites are considered insoluble, which means that all the 337 network formers in its coordination shell need to have dissolved for it to dissolve into the aqueous 338 solution. To represent the strengthening effect of Hf nearest neighbors on the Si dissolution probabilities, $339 w_{\mathrm{d}}$, we employed the formulation of Ledieu et al. (2006):

$$
w_{\mathrm{d}}(n, m)=\frac{w_{n}}{r_{\mathrm{Hf}}^{m}}
$$

341 where $n$ is the number of Si and Hf nearest neighbors, $m$ is the number of Hf nearest neighbors, and $r_{\mathrm{Hf}}$ is 342 the relative strength between $\mathrm{Si}-\mathrm{O}-\mathrm{Hf}$ and $\mathrm{Si}-\mathrm{O}-\mathrm{Si}$ linkages.

343 In all the simulations, the initial configuration of the glass was that of a slab with a perfectly smooth 344 surface with a surface area of $32 \times 32$ sites and a thickness of 4096 lattice sites. The aqueous solution 345 volume was set to be equivalent to $3.411335 \times 10^{12}$ sites. Using a side length of $0.3 \mathrm{~nm}$ for a lattice site 346 (Devreux et al., 2004), this number of aqueous sites corresponds to a $\mathrm{S} / \mathrm{V}$ ratio of $1 \mathrm{~m}^{-1}$. The parameters $347 w_{1}=0.01, w_{2}=0.001, w_{3}=0.0001$, and $w_{\mathrm{c}-\mathrm{Si}}=10$ were used in this work as was used in our previous 
work (Kerisit and Pierce, 2012) and in the work of Devreux and co-workers (Devreux et al., 2004; Ledieu et al., 2006). To represent the strong hardening effect of $\mathrm{Hf}$, the parameter $r_{\mathrm{Hf}}$ was set to an arbitrary large 350 value $\left(r_{\mathrm{Hf}}=100\right)$.

The experimental chemical compositions given in Table 2 were used as a basis for the MC 352 simulations. However, to simplify the glass compositions and isolate the effects of hafnium, aluminum 353 was considered to behave similarly to silicon and thus the $\mathrm{SiO}_{2}$ mole percent was set to be equal to the $354 \mathrm{SiO}_{2}+\mathrm{Al}_{2} \mathrm{O}_{3} \times 2$ mole percents shown in the experimental compositions. This leads to a $\mathrm{Si} / \mathrm{B}$ ratio of 2.33 355 in all five $\mathrm{HF}$ glasses, and this value was thus also used in all the $\mathrm{MC}$ simulations. 0 to $13 \mathrm{~mol} \% \mathrm{HfO}_{2}$ 356 were added to the glasses. The $\mathrm{Na}_{2} \mathrm{O}$ content was set to exactly charge compensate $\left[\mathrm{BO}_{4}\right]^{-}$and $\left[\mathrm{HfO}_{6}\right]^{2-}$ 357 groups. To mimic the single-pass flow-through experiments, a flow probability of 0.01 was used in the 358 MC simulations. More details on the approach used in the simulations for simulating the effect of flow 359 can be found in our previous publication (Kerisit and Pierce, 2012). In that study, the flow probability 360 value used here was found to yield dissolution rates equal to the forward/initial dissolution rate of sodium 361 borosilicate glasses. Here we define flow probability as the probability for removal of dissolved glass 362 components from aqueous solution. This parameters is used to simulate the effect of flow on glass 363 dissolution. In addition, to simulate the presence of silicon in the influent of the near-saturated dissolution 364 experiments, a constant silicon background concentration was added in the MC simulations. To 365 investigate the effects of the influent $\mathrm{Si}$ concentration, the silicon background concentration was varied 366 from 0 to $90 \%$ of the Si saturation concentration obtained with the model parameters given above.

\section{EXPERIMENTAL RESULTS}

\section{1 $\quad{ }^{27} \mathrm{Al},{ }^{23} \mathrm{Na},{ }^{29} \mathrm{Si}$, and ${ }^{11} \mathrm{~B}$ MAS-NMR}

369 The ${ }^{27} \mathrm{Al}$ MAS-NMR spectra (Fig. 2) collected for the HF-series glasses confirm that Al is in a 370 tetrahedral coordination, as indicated by a ${ }^{27} \mathrm{Al}$ peak maxima centered near $60 \mathrm{ppm}$. Furthermore less than

$371 \mathrm{a} \pm 0.5 \mathrm{ppm}$ shift in the ${ }^{27} \mathrm{Al}$ spectra is observed suggesting that $\mathrm{Al}$ local environment is not being 372 significantly altered with the addition of hafnium. ${ }^{27} \mathrm{Al}$ MAS-NMR spectra were fitted using the methods 
described in (Angeli et al., 2007). It was also found that using Lorentzian broadening improved the fit

374 (Fig. SI8, $0.5-0.7 \mathrm{ppm}$ ). NMR parameters are reported in Table 3 (i.e., isotropic chemical shift $\left[\delta_{\text {iso }}\right]$ and

375 quadrupolar coupling constant $\left[C_{Q}\right]$ ). As previously mentioned this fit procedure yields a constant value

of 0.6 for the quadrupolar asymmetry parameter $\left[\eta_{\mathrm{Q}}\right]$ and therefore it is omitted from Table 3 .

377 The ${ }^{23} \mathrm{Na}$ MAS-NMR spectra are reported in Fig. $3 .{ }^{23} \mathrm{Na}$ MAS-NMR spectra have been fitted 378 accounting for the distribution of the NMR parameters (Angeli et al., 2007). It was found that a small 379 Lorentzian broadening (same for all samples $4.3 \mathrm{ppm}$, this might reflective of small amount of 380 paramagnetic impurities such as Fe) improve the fit (Fig. SI9). NMR parameters are given in Table 4. A 381 small decrease of the mean value of the $\delta_{\text {iso }}$ with Hf content increasing is observed.

The ${ }^{29} \mathrm{Si}$ MAS-NMR spectra shown in Fig. 4 confirms the dominant local coordination for Si-atoms within the HF-series glasses are tetrahedral $\left({ }^{[4]} \mathrm{Si}\right)$ with corresponding resonances centered near $-95 \mathrm{ppm}$. 384 As the hafnium content in the glass increases the peaks near $-95 \mathrm{ppm}$ slightly shifts from a peak 385 maximum of -96 ppm for HF-1 to a peak maximum of -94 ppm for HF-5, with a lower broadening.

Fig. 5 shows the ${ }^{11}$ B MAS-NMR spectra for the hafnium formulation (HF) glass series (HF-1, Hf-3, 387 HF-4, and HF-5). Signals from trigonal $\left({ }^{[3]} \mathrm{B}\right)$ and tetrahedral $\left({ }^{[4]} \mathrm{B}\right)$ groups are both present. The broader 388 band centered around $13 \mathrm{ppm}$ corresponds to ${ }^{[3]} \mathrm{B}$, whereas the sharper peak centered around $-2 \mathrm{ppm}$ 389 corresponds to ${ }^{[4]} \mathrm{B}$. An increase of the ${ }^{[3]} \mathrm{B}$ fraction with the Hf content increasing is clearly observed, 390 along with only a slight modification of the ${ }^{[3]} \mathrm{B}$ lineshape (see Fig. 5 inset) and a shift of the ${ }^{[4]} \mathrm{B}$ line to 391 higher chemical shifts. In the case of the broad peak for the ${ }^{[3]} \mathrm{B}$ results from the presence of two sites: 392 boron surrounded by bridging bonds in boroxyl rings $\left(\mathrm{BO}_{3}(\mathrm{~B})\right)$ or other borate units involving $\mathrm{B}-\mathrm{O}-\mathrm{B}$ 393 bonds and boron distributed in silicate units $\left(\mathrm{BO}_{3}(\mathrm{Si})\right)$ (Angeli et al., 2010; Du and Stebbins, 2003a, b, 394 2005; Pierce et al., 2010). These results are consistent with previous results collected on other borosilicate 395 glasses that contain high-field strength cations, such as hafnium, titanium, and zirconium (Angeli et al., 396 2010; Bergeron et al., 2010). This is also consistent with the Raman band observed between 1400 and $3971480 \mathrm{~cm}^{-1}$, which is directly associated with changes in B local structure. Additional analysis of the 
spectra was required to quantify the percentage of $\mathrm{BO}_{3}(\mathrm{~B})$ and $\mathrm{BO}_{3}(\mathrm{Si})$ and is discussed in the sections to follow. Although the ${ }^{11} \mathrm{~B}$ MAS-NMR collected at $11.7 \mathrm{~T}$ are discussed in detail, similar ${ }^{11} \mathrm{~B}$ MAS-NMR measurements were also performed at higher field [i.e., $17.6 \mathrm{~T}(750 \mathrm{MHz})$ and $20 \mathrm{~T}(850 \mathrm{MHz})$ ]

401 illustrated that the $\mathrm{N}_{4}$ fraction $\left(\mathrm{N}_{4}={ }^{[4]} \mathrm{B} /\left({ }^{[4]} \mathrm{B}+{ }^{[3]} \mathrm{B}\right)\right.$ measured at each field was within 1 to $2 \%$ of each 402 other (see Fig. SI10).

\subsection{Dissolution Experiments on HF Series Glasses} state conditions were achieved (see Fig. SI11). Average steady-state normalized dissolution rates in dilute and silica saturated experiments are listed in Table 5 along with the experimental conditions, including average steady-state element concentrations, flow-through rates, and coupon surface areas. In all experiments the $\mathrm{Al}$ and $\mathrm{Hf}$ concentrations were below the detection limit and the $\mathrm{B}$ and $\mathrm{Na}$ concentrations for HF-5S glass sample tested under near-saturated conditions was below the detection limit; therefore the value for this experiment represents a maximum rate. All experimental uncertainties reported in Table 5 412 are $2 \sigma$ errors.

Dissolution rates under dilute conditions and $\mathrm{pH}\left(23^{\circ} \mathrm{C}\right)=9.0$ decreased with increasing Hf-content of 414 the glass (Fig. 6). For the HF-1 glass composition, the average dissolution rate, based on B, is 3.20( \pm 0.47$)$

$415 \times 10^{-1} \mathrm{~g} /\left(\mathrm{m}^{2} \mathrm{~d}\right)$ for HF-1D; whereas, the average dissolution rate, based on $\mathrm{B}$, for the HF-5 glass 416 composition under dilute conditions is $2.87( \pm 0.54) \times 10^{-3} \mathrm{~g} /\left(\mathrm{m}^{2} \mathrm{~d}\right)$ for HF-5D. This corresponds to a $112 \times$ 417 decrease in the dissolution rate over the glass series from 0 to $20 \mathrm{~mol} \% \mathrm{HfO}_{2}$. Similarly under near418 saturated conditions and $\mathrm{pH}\left(23^{\circ} \mathrm{C}\right)=8.0$ dissolution rates decrease from $9.58( \pm 1.68) \times 10^{-2} \mathrm{~g} /\left(\mathrm{m}^{2} \mathrm{~d}\right)$ for 419 HF-1S to $1.29( \pm 0.30) \times 10^{-4} \mathrm{~g} /\left(\mathrm{m}^{2}\right.$ d) for HF-4S, which corresponds to a $74 \times$ decrease in the dissolution 420 rate over the glass series from 0 to $15 \mathrm{~mol}^{2} \mathrm{HfO}_{2}$. As previously mentioned, $\mathrm{B}$ and $\mathrm{Na}$ concentrations for 421 the HF-5S sample (20 mol\% $\mathrm{HFO}_{2}$ glass under saturated conditions) was at or below the detection limit. 422 Using the detection limit to estimate the dissolution rate would result in $<2.62 \times 10^{-4} \mathrm{~g} /\left(\mathrm{m}^{2} \mathrm{~d}\right)$ and 
$423<3.78 \times 10^{-4} \mathrm{~g} /\left(\mathrm{m}^{2} \mathrm{~d}\right)$ for HF-5S, based on B and Na release respectively. Saturated experiments were 424 conducted at $\mathrm{pH}\left(23^{\circ} \mathrm{C}\right)=8.0$ to control the speciation of dissolved $\mathrm{Si}$ which is $100 \%$ and $\sim 90 \%$ $425 \mathrm{H}_{4} \mathrm{SiO}_{4}(\mathrm{aq})$ at $\mathrm{pH}\left(23^{\circ} \mathrm{C}\right)=8.0$ and 9.0, respectively. The effect $\mathrm{Si}$ saturation state has on the dissolution 426 rate of borosilicate glass dissolution has been well document and is directly related to the presence of $427 \quad \mathrm{H}_{4} \mathrm{SiO}_{4}(\mathrm{aq})$ (Grambow, 1985; Grambow and Müller, 2001). at $\mathrm{pH}\left(23^{\circ} \mathrm{C}\right)=8.0$ and 9.0 to evaluate the impact $\mathrm{pH}$ has on the dissolution rate under near-saturated conditions. Results suggest that increasing $\mathrm{pH}$ causes the dissolution rate, based on B release, to increase

431 from $9.58( \pm 1.68) \times 10^{-2} \mathrm{~g} /\left(\mathrm{m}^{2} \mathrm{~d}\right)$ at $\mathrm{pH}\left(23^{\circ} \mathrm{C}\right)=8.0$ to an average rate at $\mathrm{pH}\left(23^{\circ} \mathrm{C}\right)=9.0$ of $4323.07( \pm 0.32) \times 10^{-1} \mathrm{~g} /\left(\mathrm{m}^{2} \mathrm{~d}\right)$ for the two replicates. Similarly, the dissolution rates based on Na release increased from $1.19( \pm 0.21) \times 10^{-1} \mathrm{~g} /\left(\mathrm{m}^{2} \mathrm{~d}\right)$ to an average rate of $4.04( \pm 0.39) \times 10^{-1} \mathrm{~g} /\left(\mathrm{m}^{2} \mathrm{~d}\right)$ at $\mathrm{pH}\left(23^{\circ} \mathrm{C}\right)=8.0$ and 9.0 , respectively. These results illustrate roughly a $3.2 \times$ and $3.4 \times$ difference between the rates measured at $\mathrm{pH}\left(23^{\circ} \mathrm{C}\right)=8.0$ and 9.0 for $\mathrm{B}$ and $\mathrm{Na}$, respectively.

\section{DISCUSSION}

\section{$437 \quad 4.1 \quad$ Effect of $\mathrm{Hf}$ on ${ }^{29} \mathrm{Si}$ and ${ }^{11} \mathrm{~B}$ coordination}

438 Although the presence of tetrahedral Al and B in glasses are known to have an effect on the Si peak 439 position (Hålenius et al., 2010; Lippmaa et al., 1980; Lippmaa et al., 1981; Nanba et al., 2009; 440 Soleilhavoup et al., 2010), an effect related to the shielding of the Si framework by the addition of Al or $441 \mathrm{~B}$, the shift to more positive values observed for these glasses are almost certainly due to the addition of 442 hafnium. The fraction of $\mathrm{Al}$ and ${ }^{[4]} \mathrm{B}$ contained in these samples decreases by $0.75 \mathrm{~mol} \%$ and $3.2 \mathrm{~mol} \%$, 443 respectively, from HF-1 to HF-4; but instead of the peak positioning shifting to more negative values or 444 remaining the same, it moves in the direction of more positive values (Fig. 4). This is somewhat counter 445 intuitive because a decrease in the ${ }^{[4]} \mathrm{Al}$ and ${ }^{[4]} \mathrm{B}$ content should result in the Si spectra shifting to more

446 negative values or staying the same which would be consistent with the formation of $Q^{n}$ species equal to 447 or greater than 3 or the similar distribution of these species. This behavior is consistent with X-ray 
absorption fine-structure (XAFS) spectroscopy measurements of select glass samples which revealed that

449 hafnium is octahedral coordinated $\left[\mathrm{HfO}_{6}\right]^{2-}$ and resembles a hafnium metallasiloxane compound (Caulder 450 et al., 2000; Motevalli et al., 1993; Strachan et al., 2001; Zhao et al., 2000) [see Fig. SI12]. The hafnium 451 metallasiloxane moieties in these glasses consist of octahedral coordinated hafnium that is connected to 452 siloxane ring units (Caulder et al., 2000; Motevalli et al., 1993). Although the current assessment is 453 qualitative, these results suggests an increase in the number of $\mathrm{Si}-\mathrm{O}-\mathrm{Hf}$ bonds mainly at the expense of $454{ }^{[4]} \mathrm{B}-\mathrm{O}-\mathrm{Si}$ bonds and is consistent with the Raman results (see supplemental information Fig. SI13455 SI15). Note the decrease in ${ }^{[4]} \mathrm{B}-\mathrm{O}-\mathrm{Si}$ bonds is associated with the availability of $\mathrm{Na}_{2} \mathrm{O}$ and is discussed 456 in greater detail next. specifically tetrahedral borate groups surrounded by either four $\mathrm{Si}\left({ }^{[4]} \mathrm{B}(0 \mathrm{~B}, 4 \mathrm{Si})\right)$ or three $\mathrm{Si}$ and one $\mathrm{B}$ $\left.{ }^{[4]} \mathrm{B}(1 \mathrm{~B}, 3 \mathrm{Si})\right)$. This deconvolution into (at least) two components was previously discussed in Angeli et al. (2010) and stems from the analysis of the Spinning Sidebands manifold using the TOP method 461 (Massiot et al., 2006), as shown in Fig. 7 (see Fig. SI16 for TOP method results for other samples). Indeed, at least two sites can be distinguished for the ${ }^{[4]} \mathrm{B}$ line, one characterized by a larger $(\sim 1.2 \mathrm{ppm})$ and narrower ( -1.8 ppm) Spinning Sidebands manifold (see Fig. SI4 and Fig. SI5). This suggests two sites with different quadrupolar interactions. Similar features appear in the MQMAS spectrum, as shown in Fig. 8, where a continuous increase of the line width (reflective of the quadrupolar interaction strength) 466 is observed for an increase of the isotropic chemical shifts (see Fig. SI17 for MQMAS results for other 467 samples). 469 in Fig. 9 where the asymmetrical lineshape of the isotropic projection require the use of (at least) two 470 components. Using all these constraints from the MQMAS data, the MAS-NMR spectra could be fitted 471 simultaneously using four components as described in Table 6 (see Fig. SI18 and Fig. SI19). The 472 quantification of the boron sites is reported in Table 7. The variation of the $\mathrm{N}_{4}$ fraction (ratio of ${ }^{[4]} \mathrm{B}$ to 
total B), as extracted from the analysis of the ${ }^{11}$ B MAS NMR spectra, as shown in Fig. 10 shows a decrease with increasing $\mathrm{HfO}_{2}$ content. This is the result of $\mathrm{Na}_{2} \mathrm{O}$ being used to charge compensate for the addition of hafnium in the glass. The $\mathrm{N}_{4}$ fraction for HF-2 was estimated using Eqn. (6):

$$
N_{4}=-0.752 \mathrm{HfO}_{2}+0.7616
$$

Eqn. (6) was obtained plotting the $\mathrm{N}_{4}$ fraction as a function of $\mathrm{mol} \% \mathrm{HfO}_{2}$ for $\mathrm{HF}-1$, HF-3, HF-4, and HF-5 and conducting a linear regression. These results suggest that $\mathrm{Na}_{2} \mathrm{O}$ preferentially charge compensates with $\mathrm{Al}_{2} \mathrm{O}_{3}$ and $\mathrm{HfO}_{2}$ and only the residual $\mathrm{Na}_{2} \mathrm{O}$ is available to charge compensate for $\mathrm{B}_{2} \mathrm{O}_{3}$ to form ${ }^{[4]} \mathrm{B}$. Previous studies have reported a similar behavior for other alkali aluminoborosilicate glasses (El-Damrawi et al., 1993; Pierce et al., 2010), but this is the first time this has been observed in $\mathrm{HfO}_{2}$ bearing alkali alumino-borosilicate glasses. The results shown in Fig. 10 illustrate that as the $\mathrm{HfO}_{2}$ content increases from 0 mol\% for HF-1 to 20 mol\% for HF-5 the $\mathrm{N}_{4}$ fraction decreases from $75.5 \%$ to $60.2 \%$, respectively.

Although the mechanism that governs the preferred order that $\mathrm{Na}_{2} \mathrm{O}$ charge compensates for specific structural units in glass is not fully understood, studies have used the Pauling bond valence theory as a plausible model to structurally and chemically explain the observed behavior (Pauling, 1929). The bond valence theory is based on Pauling's second rule and has been used to provide insight to the structure of crystals (Brown, 1981), glasses (Cormier et al., 2000; Rossano et al., 2002), and silicate melts (Calas et al., 2014; Ellison and Hess, 1994). Pauling's second rule requires the sum of bond valences (defined as the formal charge of an ion divided by its coordination number) to all ions to equal the absolute value of their formal charges to within \pm 0.05 valance units $(v u)$. Recently, Connelly et al. (2011a) used a modified bond valence concept (i.e., coordination stabilization index [CSI]) to qualitatively predict a hierarchy for sodium to preferentially charge compensate for specific structural units in complex oxide glasses. The CSI is defined as:

$$
\mathrm{CSI}=S_{n c}-S_{c c}
$$


where $S_{n c}$ is the stability of a species stable in glass without alkali charge compensation in $v u$ and $S_{c c}$ is the stability of a species stable in glass with alkali charge compensation in $v u$. The simplified CSI model does not account for changes in bond length which will almost certainly vary with glass composition. Both $S_{n c}$ and $S_{c c}$ are calculated using the ratio of the species valence to the coordination number. For example, aluminum occurs in both 6-fold $\left({ }^{\mathrm{VI}} \mathrm{Al}^{3+}\right)$ and 4 -fold $\left({ }^{\mathrm{IV}} \mathrm{Al}^{3+}\right)$ coordination in glass; therefore $S_{n c}$ for ${ }^{\mathrm{VI}} \mathrm{Al}=$

$5020.5 v u$ and $S_{c c}$ for ${ }^{\mathrm{IV}} \mathrm{Al}=0.75 v u$ which corresponds to a CSI $=-0.25 v u$. In glass, hafnium predominantly 503 occurs in both 8-fold $\left({ }^{\mathrm{VIII}} \mathrm{Hf}^{4+}\right)$ and 6-fold $\left({ }^{\mathrm{VI}} \mathrm{Hf}^{4+}\right)$ coordination and boron predominantly occurs in 3-fold $504 \quad\left({ }^{\mathrm{III}} \mathrm{B}^{3+}\right)$ and $4-$ fold $\left({ }^{\mathrm{IV}} \mathrm{B}^{3+}\right)$ coordination. Based on these calculations the CSI is $-0.25 v u$ for $\mathrm{Al},-0.17 v u$ for $505 \mathrm{Hf}$, and $+0.25 \mathrm{vu}$ for B suggesting sodium charge compensation occurs in the following order: ${ }^{\mathrm{IV}} \mathrm{Al}>{ }^{\mathrm{VI}} \mathrm{Hf}$ $506>{ }^{\mathrm{IV}} \mathrm{B}$ for this glass series, a result consistent with the NMR results discussed in this section.

507 Lastly, also shown in Fig. 10 are the results collected by Angeli and colleagues (Angeli et al., 2008; 508 Bergeron et al., 2010) for Hf-bearing and Zr-bearing soda-lime borosilicate glass formulations. Both 509 zirconium and hafnium form octahedral structures in the borosilicate glasses; therefore the data collected on soda-lime borosilicate glass formulations by Angeli and colleagues were included and used to provide 511 insight into the behavior of hafnium in the glasses evaluated in this study. Although the trend is similar 512 the magnitude of the decrease in the $\mathrm{N}_{4}$ fraction is different for the glasses examine in this study 513 compared to soda-lime borosilicate glasses and arise because of differences in composition. The 514 borosilicate glasses studied by Angeli and colleagues contained calcium, but did not contain aluminum; 515 both elements are known to have an impact on the $\mathrm{N}_{4}$ fraction (Angeli et al., 2010; Pierce et al., 2010).

\subsection{Comparison of rates measured under dilute and near-saturated conditions}

517 To compare the rates measured under dilute and near saturated conditions, the rates measured in 518 experiments conducted at $\mathrm{pH}\left(23^{\circ} \mathrm{C}\right)=8.0$ in saturated solutions were adjusted using Eqn. (8).

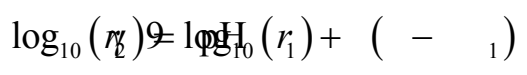

In Eqn. (8) the $r_{2}$ is the $\mathrm{pH}$-corrected rate $\left[\mathrm{g} /\left(\mathrm{m}^{2} \mathrm{~d}\right)\right] ; r_{1}$ is the uncorrected rate $\left[\mathrm{g} /\left(\mathrm{m}^{2} \mathrm{~d}\right)\right] ; \gamma$ is the $\mathrm{pH}$ power law coefficient (dimensionless); and $\mathrm{pH}_{1}$ is the $\mathrm{pH}$ of the test solution. The power law coefficient 
$522(\gamma=0.25)$ was derived by performing is linear regression on the results collected for HF-1 at $523 \mathrm{pH}\left(23^{\circ} \mathrm{C}\right)=8.0$ and 9.0 under near saturated conditions.

524 A comparison of the rates collected under dilute and saturated conditions shows that the decrease in 525 element release rates with increasing $\mathrm{HfO}_{2} \mathrm{~mol} \%$ in the glass is not as strong as in silica saturated 526 solutions (Fig. 11). For example, a comparison between the HF-1D and HF-1S rates (collected under 527 dilute and saturated conditions) show a $1.8 \times$ difference in rate, whereas a comparison of the same data for 528 HF-4D and HF-4S shows a $7 \times$ difference in the rates. These results illustrate that the addition of 529 high-field strength cations have a significant impact on the dissolution rate of aluminoborosilicate glass. 530 Changes in the structure through the distribution of $\mathrm{Si}-\mathrm{O}-\mathrm{Hf}$ bonds, which makes the glass network 531 increasingly resistant to hydrolysis, with increasing hafnium content explains a portion of the observed 532 decrease.

533 Comparing these results to dissolution rates measured by Bergeron et al. (2010) on Hf-bearing soda534 lime borosilicate glasses (Fig. 11). These experiments were conducted under dilute conditions at $535 \mathrm{~T}=90^{\circ} \mathrm{C}, \mathrm{pH}\left(23^{\circ} \mathrm{C}\right)=7.0$, and krypton adsorption Brunauer-Emmett-Teller (Kr-BET) (Brunauer et al., 536 1938). Due to the differences in experimental conditions between the two studies, the results from 537 Bergeron et al. (2010) were normalized to the experimental conditions conducted in this study (see 538 Supplemental Information). A comparison of these results suggests the rates measured by Bergeron et al. 539 (2010) are comparable, but slightly faster than the rates measured in this study. The slightly higher rates 540 are probably the result of aluminum being absent from the Hf-bearing and Zr-bearing soda-lime 541 borosilicate glasses tested by Bergeron et al. (2010).

\section{$542 \quad 4.3 \quad$ Effect of Hf on dissolved Si at glass-fluid interface}

543 Monte Carlo simulations of the HF glass-water reaction were conducted to determine why the glass

544 dissolution rate is affected by the concentration of $\mathrm{Si}$ in the influent solution. The main objective was to 545 determine the reason for the deviation in dissolution rates measured under dilute and near saturated 546 conditions. Fig. 12(a) shows the $\mathrm{B}$ release rates as a function of $\mathrm{HfO}_{2}$ mole percent relative to that 
calculated at $0 \mathrm{HfO}_{2} \mathrm{~mol} \%$ and Fig. 12(b) shows the same data but presented as a function of the percentage of Si saturation concentration and relative to the B release rate obtained in dilute conditions. Each data point represents the average of five different simulations. All the simulations were run for 80,000 steps or until the glass slab dissolved entirely, whichever came first.

It should be noted that some of the simulations predicted the formation of a blocking layer at the 552 glass-water interface through which water does not percolate, as is observed during simulations of the 553 dissolution of sodium borosilicate glasses in static conditions (Aertsens, 1999; Devreux et al., 2001; 554 Devreux et al., 2004; Kerisit and Pierce, 2012). In static conditions, as the Si concentration in solution 555 increases due to the glass dissolution through hydrolysis, Si condensation at the glass surface becomes 556 increasingly prominent and the combined effects of hydrolysis and condensation reactions lead to a decrease in the proportion of Si sites with a low number of connections to nearest-neighbor Si sites in favor of Si sites with a high number of such connections, which will be referred to as low-connectivity and high-connectivity sites, respectively. As this process is more advanced in the upper part of the altered layer, which has been in contact with the aqueous solution the longest, a dense Si layer can form eventually and thus prevents water from corroding the glass further.

In the conditions simulated here, the overall process is similar except that the source of silicon that deposits on the surface comes predominantly from the influent rather than from the dissolving glass due to the high flow and the presence of $\mathrm{Si}$ in the influent. Consequently, the likelihood for forming a blocking layer increases with increasing Si concentration in the influent. Additionally, as discussed in more detail below, the presence of Hf strengthens the altered layer and provides strong binding sites for 567 silicon atoms that deposit on the surface. Therefore, the likelihood for forming a blocking layer also 568 increases with increasing Hf content. As a result, a blocking layer formed within the time scale of the 569 simulations for all glasses containing Hf when the Si concentration in the influent was $80 \%$ or $90 \%$ of the $570 \mathrm{Si}$ saturation concentration as well as for $\mathrm{HfO}_{2}$ contents of at least $4.5 \%, 8.3 \%$, and $11.5 \%$ when the $\mathrm{Si}$ 571 influent concentrations were 70,50 , and $25 \%$ of the Si saturation concentration, respectively. In instances 
572 where a blocking layer formed, the B release rate was calculated from the period of time preceding its

573 formation. As the blocking layer forms more rapidly with increasing Si concentration in the influent and

$574 \mathrm{HfO}_{2}$ content, the $\mathrm{B}$ release rates determined in high $\mathrm{Si}$ influent concentrations and $\mathrm{HfO}_{2}$ mole percents

575 were extracted from fewer data points and thus carried higher uncertainties. Therefore, linear regressions

576 that yielded $\mathrm{R}^{2}$ values of less than 0.99 are not shown in Fig. 12.

The main finding, illustrated in Fig. 12(a), is that the extent of the decrease in the B release rate, relative to that determined for glasses without $\mathrm{Hf}$, is dependent on the influent Si concentration, with

579 steeper drops for larger amounts of $\mathrm{Si}$ in the influent. This trend is in qualitative agreement with the 580 experimental results shown in Fig. 10 and 11. To explain this phenomenon, we first note that, in dilute 581 conditions, there is essentially no condensation of $\mathrm{Si}$ at the surface and the decrease in rate with 582 increasing Hf content is solely due to the strengthening effect of Hf, which makes the glass more difficult 583 to dissolve. As the Si influent concentration increases, the rate of Si condensation at the glass surface also 584 increases. For glasses that do not contain Hf, the hydrolysis and condensation reactions take place as 585 described above, where low-connectivity sites are easily detached and the proportion of high-connectivity 586 site increases. As the Hf content is increased, Hf atoms exposed at the surface provide sites where silicon 587 atoms that deposit from the influent onto the surface can bind strongly. Because of this effect, 588 newly-formed low-connectivity sites that would otherwise be dissolved easily now have a much longer 589 residence time at the glass surface. This process, in effect, provides a greater density of anchor points 590 from which altered layers can form with greater Si densities than in the absence of Hf. As a result and as 591 illustrated in Fig. 13, water penetrates the glass at an even slower rate when the influent contains Si than 592 in dilute conditions and thus the B release rate decreases to a greater extent. Fig. 12(b) offers a different 593 way to visualize this effect. Indeed, it shows that, although the B release rates do decrease with increasing 594 Si influent concentration in the absence of Hf, as is seen experimentally, the extent of decrease becomes 595 more significant as the $\mathrm{HfO}_{2}$ content is raised. Therefore, the experimental observation that the effect of 596 Hf is greater in near-saturated conditions is explained by the Monte Carlo simulations to be due to an 

of silicon at the glass surface in the presence of Hf.

To conclude this section, there are two effects of the presence of Hf on glass dissolution: (1)

600 strengthening of the glass network and (2) stronger binding at the surface of Si condensing from aqueous

601 solution. The first effect can be isolated in the simulations in dilute conditions and the role of the second

602 effect increases as the Si concentration in the influent is increased. The two parts of Fig. 12 allow for a

603 quantitative determination of these two effects. For example, Fig. 12(a) shows that strengthening of the

604 glass network leads to a $\sim 50 \%$ reduction in dissolution rate when $10 \mathrm{~mol} \% \mathrm{HfO}_{2}$ is added to the glass and

605 Fig. 12(b) shows that stronger surface binding in the presence of Hf results in a $\sim 55 \%$ reduction in

606 dissolution rate of the glass with $10 \mathrm{~mol} \% \mathrm{HfO}_{2}$ when the influent concentration is $70 \%$ of the $\mathrm{Si}$

607 saturation concentration.

\section{CONCLUDING REMARKS}

609 The addition of high-field strength cations into the structure of borosilicate glass has a significant 610 impact on its dissolution rate. Changes in the structure of network former elements, specifically boron, 611 and the distribution of $\mathrm{Si}-\mathrm{O}-\mathrm{Hf}$ bonds with increasing hafnium content explains a portion of the 612 observed decrease in the dissolution rate. The divergence in magnitude between the average steady-state 613 release rates measured under dilute and near-saturated conditions are the result of silicon atoms in the 614 influent binding to $\mathrm{Hf}$ atoms exposed at the surface forming a low connectivity site. Because of the longer 615 residence time of low connectivity sites at the glass surface, the density of anchor sites from which altered 616 layers can form with higher silicon densities are greater in the presence than in the absence of Hf. These 617 results highlight the importance of improving our understanding of solid-water reactions with the goal of 618 linking macroscopic reaction kinetics to nanometer scale interfacial processes. Overcoming this 619 knowledge gap is key to the advancement of multi-scale or hybrid models used to forecast contaminant 620 release from nuclear waste glass, and in a more global sense, the geochemical cycling of elements in the 621 Earth's Critical Zone. 


\section{ACKNOWLEDGMENTS}

623 This research was supported by the Oak Ridge National Laboratory (ORNL) Laboratory Directed

624 Research and Development Program, U.S. Department of Energy's (DOE) Environmental Management

625 (EM) Tank Waste Management program, DOEs Office of Science and Technology under the

626 Environmental Management Science Program (proposal number 42400), and DOE EMs Office of River

627 Protection, Immobilization of Low-Activity Waste Program funded through Washington River Protection

628 Solutions. T. Charpentier and F. Angeli would like to acknowledge the financial support of AREVA and

629 CEA. The authors would like to thank David K. Shuh for his helpful discussions on the structure of

630 hafnium in peralkaline glasses which was based on unpublished XAFS measurements. A portion of this

631 research was performed in part with the Nuclear Magnetic Resonance Spectrometers and the Molecular

632 Science Computing facilities in the William R. Wiley Environmental Molecular Sciences Laboratory, a

633 national scientific user facility sponsored by the DOE's Office of Biological and Environmental Research

634 and located at PNNL. ORNL is operated by UT-Battelle, LLC and PNNL is operated by Battelle for the

635 US DOE under Contract No.'s DE-AC05-00OR22725 and DE-AC05-76RL0-1830, respectively.

636 


\section{REFERENCES}

638 Aertsens, M. (1999) Testing the Grambow glass dissolution model by comparing it with Monte Carlo 639 simulation results. Mat. Res. Soc. Symp. Proc. 556, 409-419.

640 Angeli, F., Charpentier, T., Gaillard, M. and Jollivet, P. (2008) Influence of zirconium on the structure of 641 pristine and leached soda-lime borosilicate glasses: Towards a quantitative approach by ${ }^{17} \mathrm{O}$ MQMAS 642 NMR. J. Non-Cryst. Solids 354, 3713-3722.

643 Angeli, F., Charpentier, T., Ligny, D. and Cailleteau, C. (2010) Boron Speciation in Soda Lime 644 Borosilicate Glasses Containing Zirconium. Journal of American Ceramic Society 93, 2693-2704.

645 Angeli, F., Gaillard, M., Jollivet, P. and Charpentier, T. (2007) Contribution of ${ }^{43}$ Ca MAS NMR for 646 probing the structural configuration of calcium in glass. Chemical Physics Letters 440, 324-328.

647 Angeli, F., Villain, O., Schuller, S., Charpentier, T., de Ligny, D., Bressel, L. and Wondraczek, L. (2012) 648 Effect of temperature and thermal history on borosilicate glass structure. Physical Review B 85, 054110.

649 Arab, M., Cailleteau, C., Angeli, F., Devreux, F., Girard, L. and Spalla, O. (2008) Aqueous alteration of 650 five-oxide silicate glasses: Experimental approach and Monte Carlo modeling. J. Non-Cryst. Solids 354, $651 \quad 155-161$.

652 Bacon, D. and Pierce, E.M. (2011) Development of Long-term Behavior Models for Radioactive Waste 653 Forms, in: Ojovan, M. (Ed.), Handbook of Advanced Radioactive Waste Conditioning Technologies. 654 Woodhead Publishing Limited, Cambridge, UK, pp. 433-454.

655 Bergeron, B., Galoisy, L., Jollivet, P., Angeli, F., Charpentier, T., Calas, G. and Gin, S. (2010) First 656 investigations of the influence of ${ }^{\mathrm{IV}} \mathrm{B}$ elements (Ti, $\mathrm{Zr}$, and $\mathrm{Hf}$ ) on the chemical durability of soda-lime 657 borosilicate glasses. J. Non-Cryst. Solids 356, 2315-2322.

658 Bourcier, W.L. (1994) Waste glass corrosion modeling: Comparison with experimental results. Mat. Res. 659 Soc. Symp. Proc. 333, 69-82.

660 Brown, G.E., Jr and Calas, G. (2012) Mineral-Aqueous Solution Interfaces and Their Impact on the 661 Environment. Geochemical Perspectives 1.

662 Brown, I. (1981) The bond-valence method: an empirical approach to chemical structure and bonding, in: 663 O'Keeffe, M., Navrotsky, A. (Eds.), Structure and Bonding in Crystals. Academic Press, New York.

664 Brunauer, S., Emmett, P.H. and Teller, E. (1938) Adsorption of Gases in Multimolecular Layers. J. Am. 665 Chem. Soc. 60, 309-319.

666 Bunker, B.C., Arnold, G.W., Day, D.E. and Bray, P.J. (1986) The effect of molecular structure on 667 borosilicate glass leaching. J. Non-Cryst. Solids 87, 226-253.

668 Cailleteau, C., Angeli, F., Devreux, F., Gin, S., Jestin, J., Jollivet, P. and Spalla, O. (2008) Insight into 669 silicate-glass corrosion mechanisms. Nature Materials 7, 978-983.

670 Cailleteau, C.1., Devreux, F.o., Spalla, O., Angeli, F.d.r. and Gin, S.p. (2011) Why Do Certain Glasses 671 with a High Dissolution Rate Undergo a Low Degree of Corrosion? The Journal of Physical Chemistry C $672115,5846-5855$. 
Calas, G., Galoisy, L., Cormier, L., Ferlat, G. and Lelong, G. (2014) The Structural Properties of Cations in Nuclear Glasses. Procedia Materials Science 7, 23-31.

Caulder, D., Booth, C., Bucher, J., Edelstein, N., Liu, P., Lukens, W., Rao, L., Shuh, D.K., Davis, L., Darab, J., Li, H., Li, L., Strachan, D. and Allen, P. (2000) Speciation of Hafnium in Peralkaline and Peraluminous Wasteform Glasses Using XAFS Spectroscopy 219th American Chemical Society National Meeting. Division of Nuclear Chemistry and Technology, Symposium on Nuclear Waste Remediation and Long-Term Storage, San Francisco, CA.

Chick, L.A. and Pederson, L.R. (1984) The relationship between reaction layer thickness and leach rate for nuclear waste glasses. Mat. Res. Soc. Symp. Proc. 26, 635-642.

Connelly, A., Hyatt, N., Travis, K., Hand, R. and Maddrell, E. (2011a) Predicting the preference for charge compensation in silicate glasses. Physical Chemistry of Glasses: European Journal of Glass Science and Technology B 52, 64-67.

Connelly, A., Hyatt, N., Travis, K., Hand, R., Maddrell, E. and Short, R. (2011b) The structural role of Zr within alkali borosilicate glasses for nuclear waste immobilization. J. Non-Cryst. Solids 357, 1647-1656.

Cormier, L., Ghaleb, D., Delaye, J.M. and Calas, G. (2000) Competition for charge compensation in borosilicate glasses: Wide-angle x-ray scattering and molecular dynamics calculations. Physical Review B $61,14495-14499$.

Davis, J. and Kent, D. (1990) Surface complexation modeling in aqueous geochemistry, in: Hochella, M.F., Jr., White, A.F. (Eds.), Mineral-Water Interface Geochemistry. Mineralogical Society of America, Washington, DC, pp. 177-260.

Davis, L., Darab, J.G., Qian, M., Zhao, D., Palenik, C., Li, H., Strachan, D.M. and Li, L. (2003) Hafnium in peralkaline and peraluminous boro-aluminosilicate glass and glass sub-components: a solubility study. J. Non-Cryst. Solids 328, 102-122.

Devreux, F., Barboux, P., Filoche, M. and Sapoval, B. (2001) A simplified model for glass dissolution in water. J. Mater. Sci. 36, 1331-1341.

Devreux, F., Ledieu, A., Barboux, P. and Minet, Y. (2004) Leaching of borosilicate glasses. II. Model and Monte-Carlo simulations. J. Non-Cryst. Solids 343, 13-25.

Du, L.-S. and Stebbins, J.F. (2003a) Site Preference and Si/B Mixing in Mixed-Alkali Borosilicate Glasses: A High-Resolution ${ }^{11} \mathrm{~B}$ and ${ }^{17} \mathrm{O}$ NMR Study. Chemistry of Materials 15, 3913 - 3921.

Du, L.-S. and Stebbins, J.F. (2003b) Solid-state NMR study of metastable immiscibility in alkali borosilicate glasses. J. Non-Cryst. Solids 315, 239-255.

Du, L.-S. and Stebbins, J.F. (2005) Network connectivity in aluminoborosilicate glasses: a highresolution ${ }^{11} \mathrm{~B},{ }^{27} \mathrm{Al}$, and ${ }^{17} \mathrm{O}$ NMR study. J. Non-Cryst. Solids 351, 3508-3520.

El-Damrawi, G., Müller-Warmuth, W., Doweidar, H. and Gohar, I.A. (1993) ${ }^{11} \mathrm{~B},{ }^{29} \mathrm{Si},{ }^{27} \mathrm{Al}$ nuclear magnetic resonance studies of $\mathrm{Na}_{2} \mathrm{O}-\mathrm{Al}_{2} \mathrm{O}_{3}-\mathrm{B}_{2} \mathrm{O}_{3}-\mathrm{SiO}_{2}$ glasses. Phys. Chem. Glasses 34, 52-57. 
Ellison, A. and Hess, P. (1994) Raman study of potassium silicate glasses containing $\mathrm{Rb}^{+}, \mathrm{Sr}^{2+}, \mathrm{Y}^{3+}$, and $\mathrm{Zr}^{4+}$ : Implications for cation solution mechanisms in multicomponent silicate liquids. Geochimica Cosmochimica Acta 58, 1877-1887.

Farges, F., Ponader, C. and Brown, G. (1991) Structural environments of incompatible elements in silicate glasses/melt systems: I. Zirconium at trace levels. Geochim. Cosmochim. Acta 55, 1563-1574.

Frugier, P., Martin, C., Ribet, I., Advocat, T. and Gin, S. (2005) The effect of composition on the leaching of three nuclear waste glasses: R7T7, AVM, and VRZ. J. Nucl. Mater. 346, 194-207.

Galoisy, L., Pélegrin, E., Arrio, M.-A., Ildefonse, P., Calas, G., Ghaleb, D., Fillet, C. and Pacaud, F. (1999) Evidence for 6-Coordinated Zirconium in Inactive Nuclear Waste Glasses. Journal of the American Ceramic Society 82, 2219-2224.

Gin, S. (2014) Open Scientific Questions about Nuclear Glass Corrosion. Procedia Materials Science 7, 163-171.

Gin, S., Abdelouas, A., Criscenti, L., Ebert, W., Ferrand, K., Geisler, T., Harrison, M., Inagaki, Y., Mitsui, S., Mueller, K., Marra, J., Pantano, C., Pierce, E.M., Ryan, J.V., Schofield, J., Steefel, C. and Vienna, J. (2013) An International Initiative on Long-term Behavior of High-Level Nuclear Waste Glass. Materials Today 16, 243-248.

Gin, S., Jollivet, P., Fournier, M., Angeli, F., Frugier, P. and Charpentier, T. (2015) Origin and consequences of silicate glass passivation by surface layers. Nature Communications 6, 1-8.

Gin, S., Ribet, I. and Couillard, M. (2001) Role and properties of the gel formed during nuclear glass alteration: importance of gel formation conditions. J. Nucl. Mater. 298, 1-10.

Grambow, B. (1985) A General Rate Equation for Nuclear Waste Glass Corrosion, in: Jantzen, C.M., Stone, J.A., Ewing, R.C. (Eds.), 1984 MRS Fall Meeting. Material Research Society Symposium Proceedings, Boston, Massachusetts, pp. 15-27.

Grambow, B. (2006) Nuclear Waste Glasses - How Durable? Elements: An International Magazine of Mineralogy, Geochemistry, and Petrology 2, 357-364.

Grambow, B. and Müller, R. (2001) First-order dissolution rate law and the role of surface layers in glass performance assessment. J. Nucl. Mater. 298, 112-124.

Hålenius, U., Skogby, H., Eden, M., Nazzareni, S., Kristiansson, P. and Resmark, J. (2010) Coordination of boron in nominally boron-free rock forming silicates: evidence for incorporation of BO3 groups in clinopyroxene. Geochimica Cosmochimica Acta 74, 5672-5679.

Hazen, R. and Finger, L. (1979) Crystal-structure and compressibility of zircon at high pressure. American Mineralogist 64, 196-201.

Helgeson, H.C., Delany, J.M., Nesbitt, H.W. and Bird, D.K. (1978) Summary and critique of the thermodynamic properties of rock-forming minerals. American Journal of Science 278, 229.

Hellman, R., Cotte, S., Cadel, E., Malladi, S., Karlsson, L., Lozano-Perez, S., Cabie, M. and Seyeux, A. (2015) Nanometre-scale evidence for interfacial dissolution-reprecipitation control of silicate glass corrosion. Nature Materials 14, 307-311. 
Herndon, E. and Brantley, S. (2011) Movement of Manganese Contamination Through the Critical Zone. Applied Geochemistry 26, S40-S43.

Herndon, E., Jin, L. and Brantley, S. (2011) Soils Reveal Widespread Manganese Enrichment from Industrial Inputs. Environmental Science and Technology 45, 241-247.

Hochella, M.F., Jr. and White, A.F. (1990) Mineral-Water Interface Geochemistry, in: Ribbe, P.H. (Ed.), Reviews in Mineralogy. Mineralogical Society of America, Washington, DC.

Hopf, J. and Pierce, E.M. (2014) Topography and Mechanical Property Mapping of International Simple Glass Surfaces with Atomic Force Microscopy. Procedia Materials Science 7, 216-222.

Icenhower, J.P., McGrail, B.P., Shaw, W.J., Pierce, E.M., Nachimuthu, P., Shuh, D.K., Rodriguez, E.A. and Steele, J.L. (2008) Experimentally determined dissolution kinetics of Na-rich borosilicate glass at far from equilibrium conditions: Implications for Transition State Theory. Geochim. Cosmochim. Acta 72, 2767-2788.

Icenhower, J.P., Strachan, D.M., McGrail, B.P., Scheele, R.D., Rodriguez, E.A., Steele, J.L. and Legore, V.L. (2006) Dissolution kinetics of pyrochlore ceramics for the disposition of plutonium. American Mineralogist 91, 39-53.

Jegou, C., Gin, S. and Larche, F. (2000) Alteration kinetics of a simplified nuclear glass in an aqueous medium: effects of solution chemistry and of protective gel properties on diminishing the alteration rate. J. Nucl. Mater. 280, 216-229.

Johnson, J., Oelkers, E.H. and Helgeson, H.C. (1992) SUPCRT92: A software package for calculating the standard molal thermodynamic properties of minerals, gases, aqueous species, and reactions from 1 to 5000 bar and 0 to $1000^{\circ} \mathrm{C}$. Computers \& Geosciences 18, 899-947.

Jollivet, P., Angeli, F., Cailleteau, C., Devreux, F., Frugier, P. and Gin, S. (2008) Investigation of gel porosity clogging during glass leaching. J. Non-Cryst. Solids 354, 4952-4958. Solids 381, 40-47.

771 Kerisit, S. and Pierce, E.M. (2011) Monte Carlo Simulations of the Dissolution of Borosilicate and 772 Aluminoborosilicate Glasses in Dilute Aqueous Solutions. Geochim. Cosmochim. Acta 75, 5296-5309.

773 Kerisit, S. and Pierce, E.M. (2012) Monte Carlo Simulations of the Dissolution of Borosilicate Glasses in 774 Near-Equilibrium Conditions. J. Non-Cryst. Solids 358, 1324-1332.

775 Kerisit, S., Pierce, E.M. and Ryan, J.V. (2015) Monte Carlo Simulations of Coupled Diffusion and 776 Surface Reactions During the Aqueous Corrosion of Borosilicate Glasses. J. Non-Cryst. Solids 408, 142777149.

778 Kerisit, S., Ryan, J.V. and Pierce, E.M. (2013) Monte Carlo Simulations of the Corrosion of 779 Aluminoborosilicate Glasses. J. Non-Cryst. Solids 378, 273-281. 
804

805

806

807

808

809

810

811

812

Larsen, F.H. and Farnan, I. (2002) ${ }^{29} \mathrm{Si}$ and ${ }^{17} \mathrm{O}$ (Q)CPMG-MAS solid-state NMR experiments as an optimum approach for half-integer nuclei having long $\mathrm{T}_{1}$ relaxation times. Chemical Physics Letters 357, 403-408.

Ledieu, A., Devreux, F., Barboux, P. and Minet, Y. (2006) Contribution of Monte Carlo modeling to understanding the alteration of nuclear glasses by water. Nucl. Sci. Eng. 153, 285-300.

Lippmaa, E., Magi, M., Samoson, A., Engelhardt, G. and Grimmer, A.R. (1980) Structural Studies of Silicates by Solid-State High-Resolution ${ }^{29}$ Si NMR. J. Am. Chem. Soc. 102, 4889-4893.

Lippmaa, E., Magi, M., Samoson, A., Tarmak, M. and Engelhardt, G. (1981) Investigation of the Structure of Zeolites by Solid-State High-Resolution ${ }^{29}$ Si NMR Spectroscopy. J. Am. Chem. Soc. 103, $4992-4996$.

Liu, C., Zachara, J., Yantasee, W., Majors, P. and McKinley, J. (2006) Microscopic reactive diffusion of uranium in contaminated sediments at Hanford, United States. Water Resources Research 42, W12420W12435.

Lobanova, M., Ledieu, A., Barboux, P., Devreux, F., Spalla, O. and Lambard, J. (2002) Effect of $\mathrm{ZrO}_{2}$ on the Glass Durability, in: McGrail, B.P., Cragnolino, G. (Eds.), Scientific Basis for Nuclear Waste Management XXV. Material Research Society, Boston, Massachusetts, pp. 571-580.

Lobanova, M., Maurer, L., Barboux, P., Devreux, F. and Minet, Y. (2001) Monte Carlo modelling of glass dissolution: Comparison with experiments. Mat. Res. Soc. Symp. Proc. 663, 237-245.

Lopez, C., Deschanel, X., Den Auwer, C., Cachia, J., Peuget, S. and Bart, J. (2005) X-ray absorption studies of borosilicate glasses containing dissolved actinides or surrogates. Physica Scripta T115, 342345.

Massiot, D., Hiet, J., Pellerin, N., Fayon, F., Deschamps, M., Steuernagel, S. and Grandinetti, P.J. (2006) Two-dimensional one pulse MAS of half-integer quadrupolar nuclei. Journal of Magnetic Resonance 181, 310-315.

McGrail, B.P., Ebert, W.L., Bakel, A.J. and Peeler, D.K. (1997) Measurement of kinetic rate law parameters on a Na-Ca-Al borosilicate glass for low-activity waste. J. Nucl. Mater. 249, 175-189.

McGrail, B.P., Icenhower, J.P., Shuh, D.K., Liu, P., Darab, J.G., Baer, D.R., Thevuthasan, S., Shutthanandan, V., Engelhard, M.H., Booth, C.H. and Nachimuthu, P. (2001) The structure of $\mathrm{Na}_{2} \mathrm{O}-$ $\mathrm{Al}_{2} \mathrm{O}_{3}-\mathrm{SiO}_{2}$ glass: impact on sodium ion exchange in $\mathrm{H}_{2} \mathrm{O}$ and $\mathrm{D}_{2} \mathrm{O}$. J. Non-Cryst. Solids 296, 10-26.

McKeown, D., Muller, I., Buechele, A., Pegg, I. and Kendziora, C. (2000) Structural characterization of high-zirconia borosilicate glasses using Raman spectroscopy. J. Non-Cryst. Solids 262, 126-134.

McKeown, D.A., Muller, I.S., Buechele, A.C. and Pegg, I.L. (1999) X-ray absorption studies of the local environment of Zr in high-zirconia borosilicate glasses. J. Non-Cryst. Solids 258, 98-109.

Motevalli, M., Shah, D. and Sullivan, A.C. (1993) Solid-state and solution structures of some lithium salts of tetraphenyldisiloxanediolate(2-) and the lithium-bridged compounds $\mathrm{Li}_{2}\left[\mathrm{M}\left(\mathrm{OSiPh}_{2} \mathrm{OSiPh}_{2} \mathrm{O}\right)_{3} \cdot 3\right.$ py $]($ py $=$ pyridine, $\mathrm{M}=\mathrm{Zr}$ or Hf). Journal of the Chemical Society, Dalton Transactions 0, 2849-2855. 
Nanba, T., Asano, Y., Benino, Y., Sakida, S. and Miura, Y. (2009) Molecular orbital calculations of the ${ }^{29} \mathrm{Si}$ NMR chemical shift in borosilicates: the effect of boron coordination to $\mathrm{SiO}_{4}$ units. Physical Chemistry of Glasses: European Journal of Glass Science and Technology B 50, 301-304.

Oelkers, E.H. and Schott, J. (2009) Thermodynamic and Kinetics of Water Rock Interactions, in: Rosso, J. (Ed.), Reviews in Mineralogy and Geochemistry. Mineralogical Society of Amercia, Chantilly, VA.

Pauling, L. (1929) The Principles Determining the Structure of Complex Ionic Crystals. J. Am. Chem. Soc. 51, 1010-1026.

Pierce, E.M. and Bacon, D. (2009) Accelerated Weathering of Waste Glass at $90^{\circ} \mathrm{C}$ with the Pressurized Unsaturated Flow (PUF) Apparatus: Implications for Predicting Glass Corrosion with a Reactive Transport Model, in: Cozzi, A., Ohji, T. (Eds.), Environmental Issues and Waste Management Technologies in the Materials and Nuclear Industries XII. John Wiley \& Sons, Inc., pp. 141-153.

Pierce, E.M. and Bacon, D. (2011) Combined Experimental and Computational Approach To Predict the Glass-Water Reaction. Nuclear Science and Technology 176, 22-39.

Pierce, E.M., Frugier, P., Criscenti, L., Kwon, K. and Kerisit, S. (2014) Modeling Interfacial Glass-water Reactions: Recent Advances and Current Limitations. International Journal of Applied Glass Science 5, 421-435.

Pierce, E.M., Icenhower, J.P., Serne, R.J. and Catalano, J. (2005) Experimental determination of $\mathrm{UO}_{2}$ (cr) dissolution kinetics: Effects of solution saturation state and pH. J. Nucl. Mater. 345, 206-218.

Pierce, E.M., Reed, L.R., Shaw, W.J., McGrail, B.P., Icenhower, J.P., Windisch, C.F., Cordova, E.A. and Broady, J. (2010) Experimental determination of the effect of the ratio of B/Al on glass dissolution along the nepheline $\left(\mathrm{NaAlSiO}_{4}\right)$ - Malinkoite $\left(\mathrm{NaBSiO}_{4}\right)$ join. Geochim. Cosmochim. Acta 74, 2634-2654.

Pierce, E.M., Richards, E.L., Davis, A.M., Reed, L.R. and Rodriguez, E.A. (2008) Aluminoborosilicate waste glass dissolution under alkaline conditions at $40^{\circ} \mathrm{C}$ : Implications for a chemical affinity-based rate equation. Environmental Chemistry 5, 73 - 85.

Putnis, A. (2015) Glass Corrosion: Sharpended Interface. Nature Materials 14, 261-262.

Quintas, A., Charpentier, T., Majerus, O., Caurant, D., Dussossoy, J.-L. and Vermaut, P. (2007) NMR Study of a Rare-Earth Aluminoborosilicate Glass with Varying CaO-to-Na2O Ratio. Applied Magnetic Resonance 32, 613-634.

Rossano, S., Farges, F., Ramos, A., Delany, J.M. and Brown, G. (2002) Bond valence in silicate glasses. J. Non-Cryst. Solids 304, 167-173.

Shannon, R. (1976) Revised effective ionic radii and systematic studies of interatomic distances in halides and chalcogenides. Acta Crystallographica A32, 751-767.

Soleilhavoup, A., Delaye, J.-M., Angeli, F., Caurant, D. and Charpentier, T. (2010) Contribution of firstprinciples calculations to multinuclear NMR analysis of borosilicate glasses. Magnetic Resonance in Chemistry 48, S159-S170.

Speer, J. and Cooper, B. (1982) Crystal structure of synthetic hafnon, $\mathrm{HfSiO}_{4}$, comparison with zircon and the actinide orthosilicates. American Mineralogist 67, 804-808. 
Steefel, C., DePaolo, D. and Lichtner, P. (2005) Reactive transport modeling: An essential tool and a new research approach for the Earth sciences. Earth and Planetary Science Letters 240, 539-558.

855 Steefel, C. and Maher, K. (2009) Fluid-rock interaction: a reactive transport approach, in: Oelkers, E.H., 856 Schott, J. (Eds.), Thermodynamics and kinetics of water-rock interaction. Mineralogical Society of 857 America, Chantilly, Virginia, pp. 485-528.

858 Strachan, D., Shuh, D.K., Ewing, R. and Vance, E. (2001) Distribution and Solubility of Radionuclides 859 and Neutron Absorbers in Waste Forms for Disposition of Plutonium Ash and Scraps, Excess Plutonium, 860 and Miscellaneous Spent Nuclear Fuels. US Department of Energy, Washington, DC.

861 Wellman, D.M., Icenhower, J.P., Gamerdinger, A.P. and Forrester, S.W. (2006) Effects of pH, 862 temperature, and aqueous organic material on the dissolution kinetics of meta-autunite minerals, $(\mathrm{Na}, \mathrm{Ca})_{2-}$ $863{ }_{1}\left[\left(\mathrm{UO}_{2}\right)\left(\mathrm{PO}_{4}\right)\right]_{2} \bullet 3 \mathrm{H}_{2} \mathrm{O}$. American Mineralogist 91, 143-158.

864 Windisch, C., Pierce, E., Burton, S. and Bovaird, C. (2011) Deep-UV Raman Spectroscopic Analysis of 865 Structure and Dissolution Rates of Silica-Rich Sodium Borosilicate Glasses. J. Non-Cryst. Solids 357 , $8662170-2177$.

867 Wolery, T.J. (1992) EQ3NR, A Computer Program for Geochemical Aqueous Speciation-Solubility 868 Calculations: Theoretical Manual, User's Guide, and Related Documentation (Version 7.0). Lawrence 869 Livermore National Laboratory, Livermore, CA, pp. 1-246.

870 Zachara, J., Ainsworth, C., Brown, G.E., Jr, Catalano, J., McKinley, J., Qafoku, O., Smith, S., Szecsody, 871 J., Traina, S. and Warner, J. (2004) Chromium speciation and mobility in a high level nuclear waste 872 vadose zone plume. Geochimica Cosmochimica Acta 68, 13-30.

873 Zhao, D., Davis, L., Li, L., Palenik, C., Wang, L., Strachan, D. and Ewing, R. (2000) Gadolinium and 874 Hafnium Alumino-Borosilicate Glasses: Gd and Hf Solubilities, in: Smith, R., Shoesmith, D. (Eds.), Scientific Basis for Nuclear Waste Management XXIII. Material Research Society, Boston, Massachusetts, pp. 683-689. 


\section{FIGURES}

880 Fig. 1 Schematic of the single-pass flow-through (SPFT) apparatus. 35

881 Fig. $2{ }^{27} \mathrm{Al}$ MAS spectra of the Hf glass series. 35

882 Fig. $3{ }^{23} \mathrm{Na}$ MAS spectra of the Hf glass series. 36

883 Fig. $4{ }^{29}$ Si MAS NMR of the Hf glass series. 36

884 Fig. $5{ }^{11}$ B MAS-NMR spectra of the Hf glass series. Inset shows the $\mathrm{BO}_{3}$ line. 37

885 Fig. 6 Dissolution Rate, in $\mathrm{g} /\left(\mathrm{m}^{2} \mathrm{~d}\right)$, for $\mathrm{B}$ as a function of $\mathrm{mol} \% \mathrm{HfO}_{2}$ in glass for experiments conducted 886 under diluted conditions and $\mathrm{pH}\left(23^{\circ} \mathrm{C}\right)=9.0$ (top) and near-saturated conditions at $\mathrm{pH}\left(23^{\circ} \mathrm{C}\right)=8.0$ 887 (bottom). The rate measured for the HF-5 sample $\left(20 \mathrm{~mol} \% \mathrm{HfO}_{2}\right)$ under near saturated conditions 888 represents a maximum value. 38

889 Fig. $7{ }^{11}$ B MAS-NMR spectrum analysis by the TOP method. Left panel shows the TOP spectrum and 890 right panel shows two columns extracted at two chemical shifts (spectra are normalized to the same 891 spinning sideband manifold maximum height). 39

892 Fig. $8{ }^{11}$ B MQMAS-NMR spectrum $\left({ }^{[4]} \mathrm{B}\right.$ region $)$ of the Hf $10 \%$ glass. Right panel shows slices extracted 893 at isotropic shifts (isotropic dimension) $-4,0$ and 3 ppm. 39

894 Fig. $9{ }^{11}$ B MQMAS spectrum $\left({ }^{[3]} \mathrm{B}\right.$ region) and its projection (of the regions between dashed line) on the 895 isotropic dimension. 40

896 Fig. 10 Comparison of the $\mathrm{N}_{4}$ fraction (ratio of ${ }^{[4]} \mathrm{B}$ to total $\mathrm{B}$ ) as a function of $\mathrm{mol} \% \mathrm{MO}_{2}$ (where $\mathrm{M}=\mathrm{Hf}$ 897 or $\mathrm{Zr}$ ) for the HF series glasses used in this study and the Hf-bearing glasses tested by 898 Bergeron et al. (2010). Also shown for comparison are the results collected on Zr-bearing glasses by 899 Bergeron et al. (2010) and Angeli et al. (2008). Note: For the HF-2 glass, the $\mathrm{N}_{4}$ fraction was estimated 900 by conducting a linear regression using the results collected for HF-1 through HF-5. 40

901 Fig. $11 \log _{10}$ (Dissolution Rate), in $\mathrm{g} /\left(\mathrm{m}^{2}\right.$ d), for $\mathrm{B}$ and $\mathrm{Na}$ as a function of $\mathrm{mol} \% \mathrm{HfO}_{2}$ in glass for 902 experiments conducted under diluted and near-saturated conditions. The B and Na values for $20 \mathrm{~mol} \%$ $903 \mathrm{HfO}_{2}$ represents a maximum value, the actual rates are much lower. 41

904 Fig. 12 Results of the Monte Carlo simulation showing (a) B release rates as a function of $\mathrm{HfO}_{2}$ content 905 relative to that at $0 \mathrm{HfO}_{2}$ mole percent for a range of Si concentrations in the influent expressed as 906 percentages of the Si saturation concentration; and (b) B release rates as a function of the Si influent 907 concentration relative to that obtained in dilute conditions for a range of $\mathrm{HfO}_{2}$ contents. 41

908 Fig. 13 Results of the Monte Carlo simulation showing the deepest glass layers reached by the aqueous 909 solution (where zero depth corresponds to the initial glass surface) as a function of computer steps for two $910 \mathrm{HfO}_{2}$ contents in dilute conditions and at $70 \%$ of the Si saturation concentration. 42 
912

913

914

915

916

917

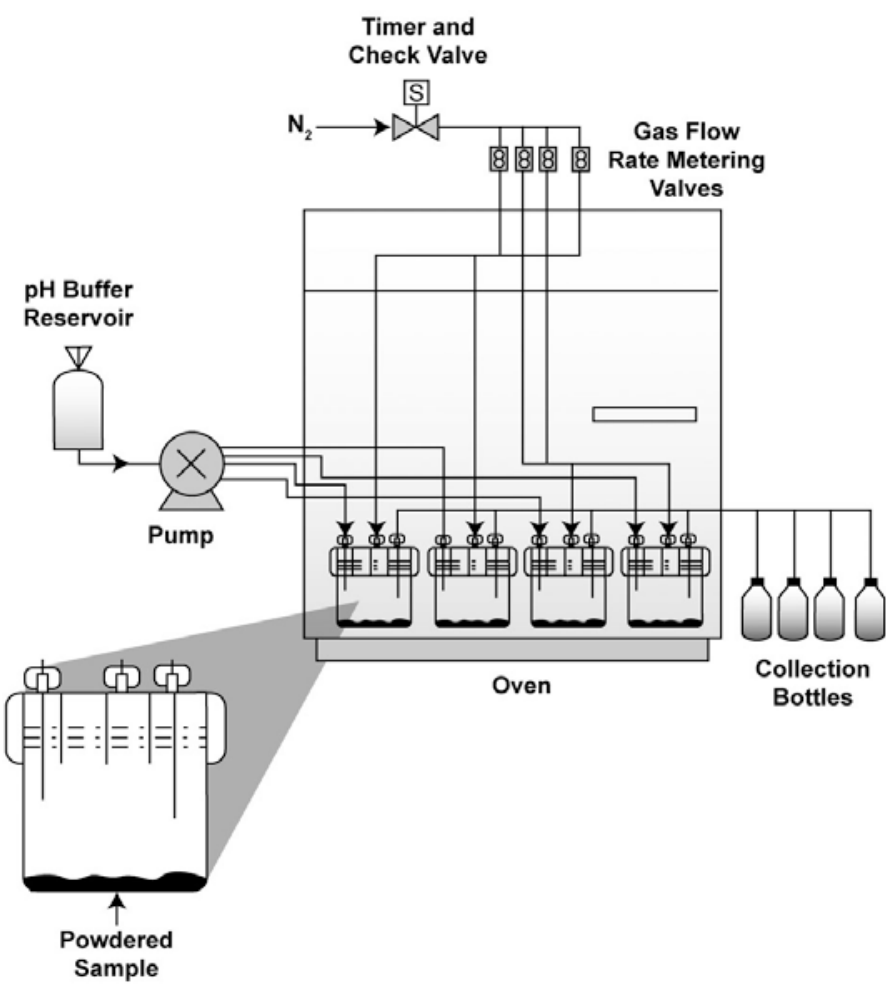

Fig. 1 Schematic of the single-pass flow-through (SPFT) apparatus.

- Hf $0 \%$

- Hf $10 \%$

- Hf $15 \%$

- Hf $20 \%$

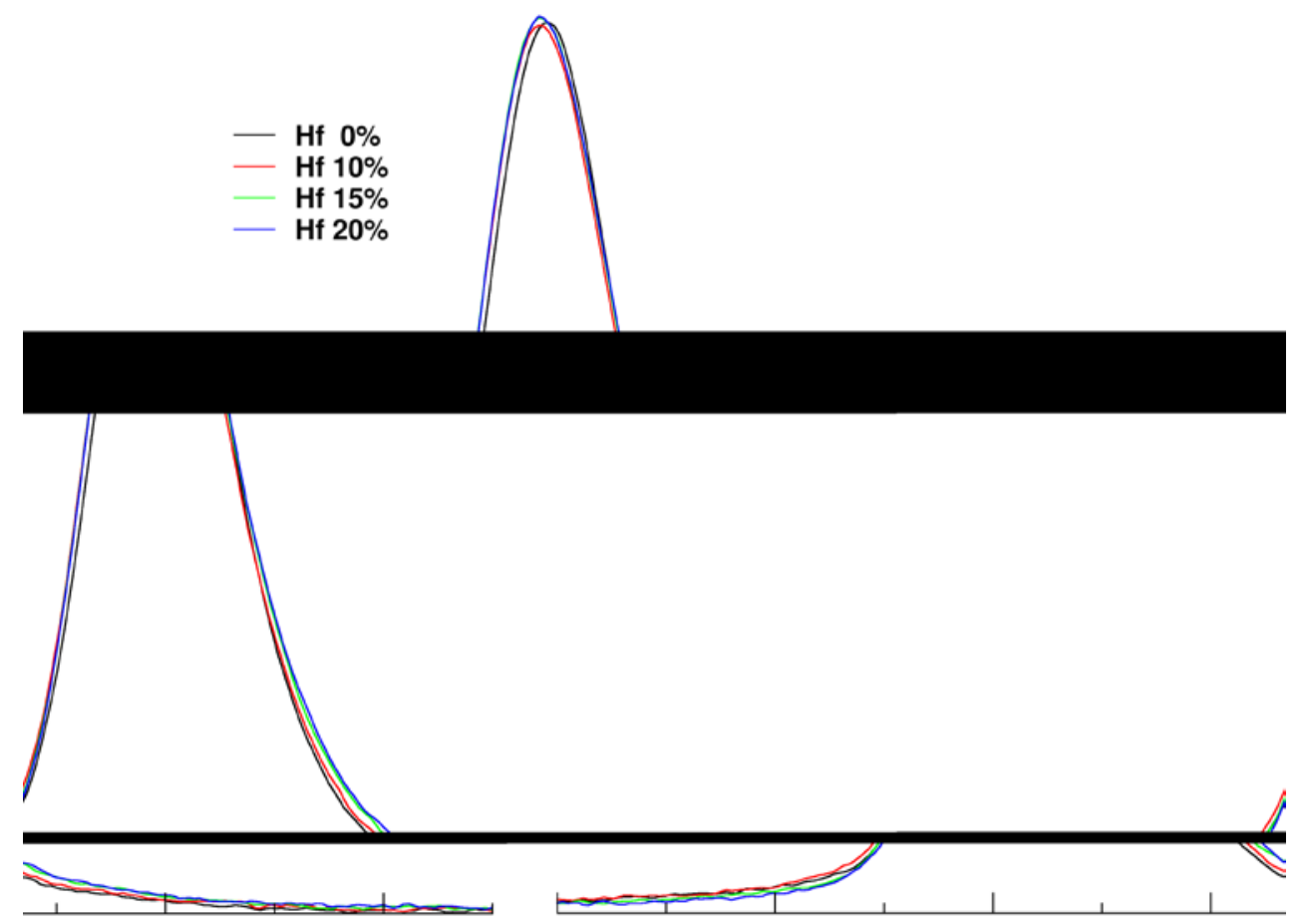

Fig. $2{ }^{27}$ Al MAS spectra of the Hf glass series. 
918

919

920

921

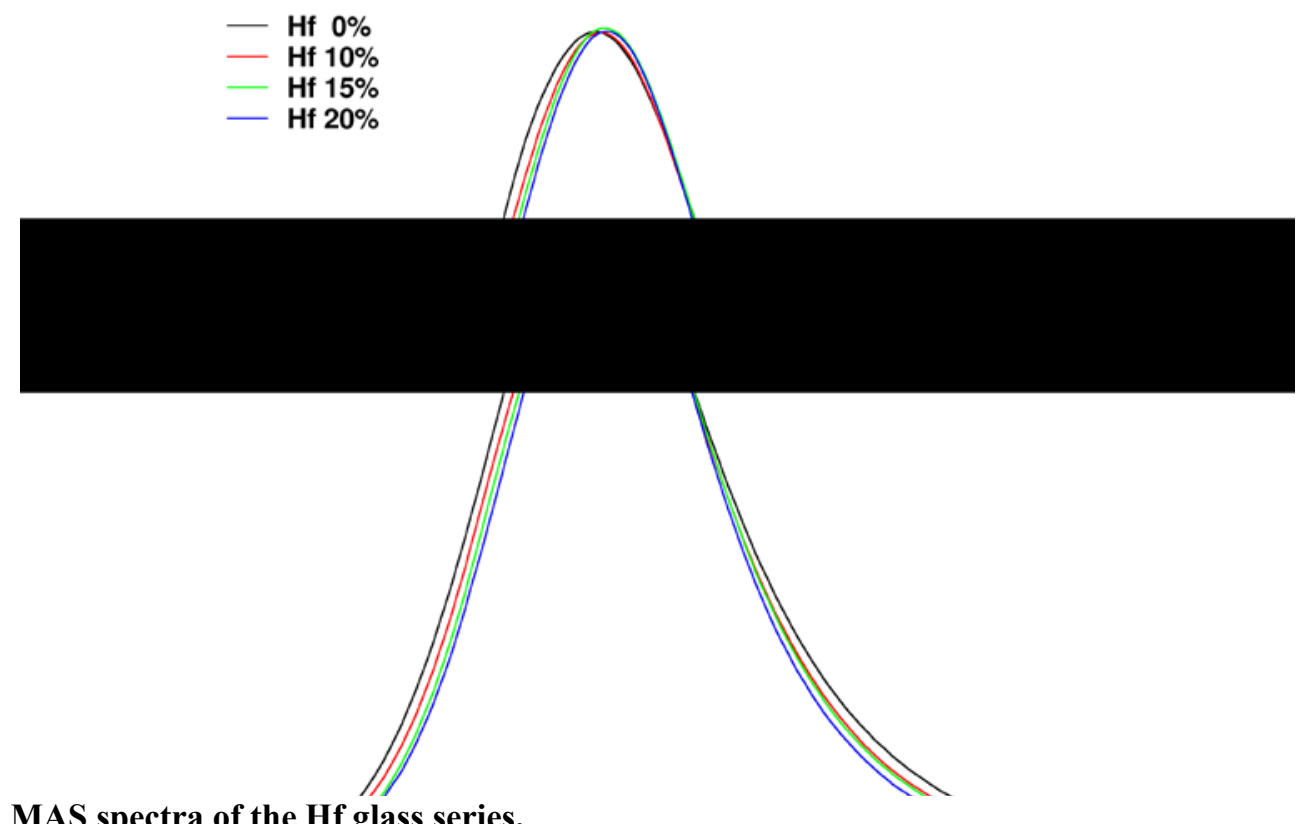

Fig. $3{ }^{23} \mathrm{Na}$ MAS spectra of the Hf glass series.
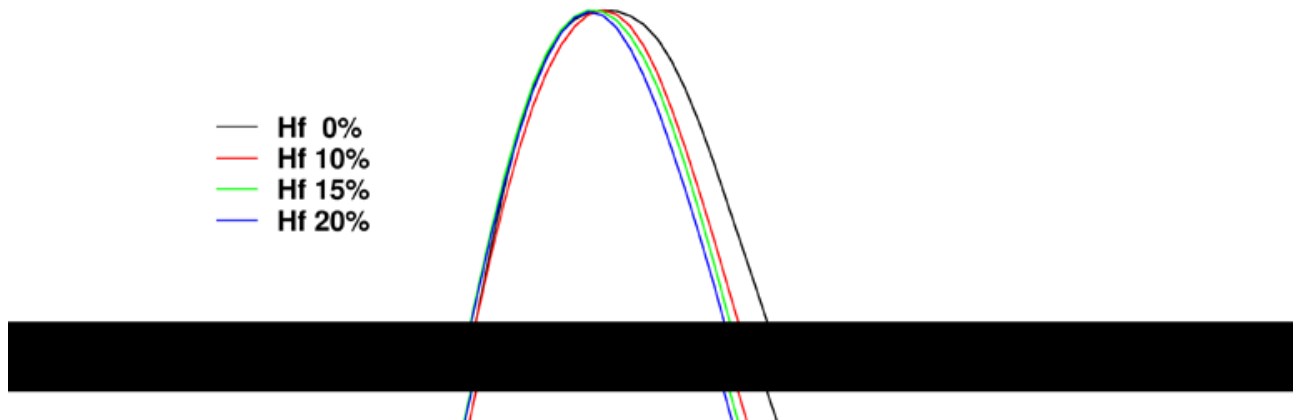

Fig. $4{ }^{29}$ Si MAS NMR of the Hf glass series. 


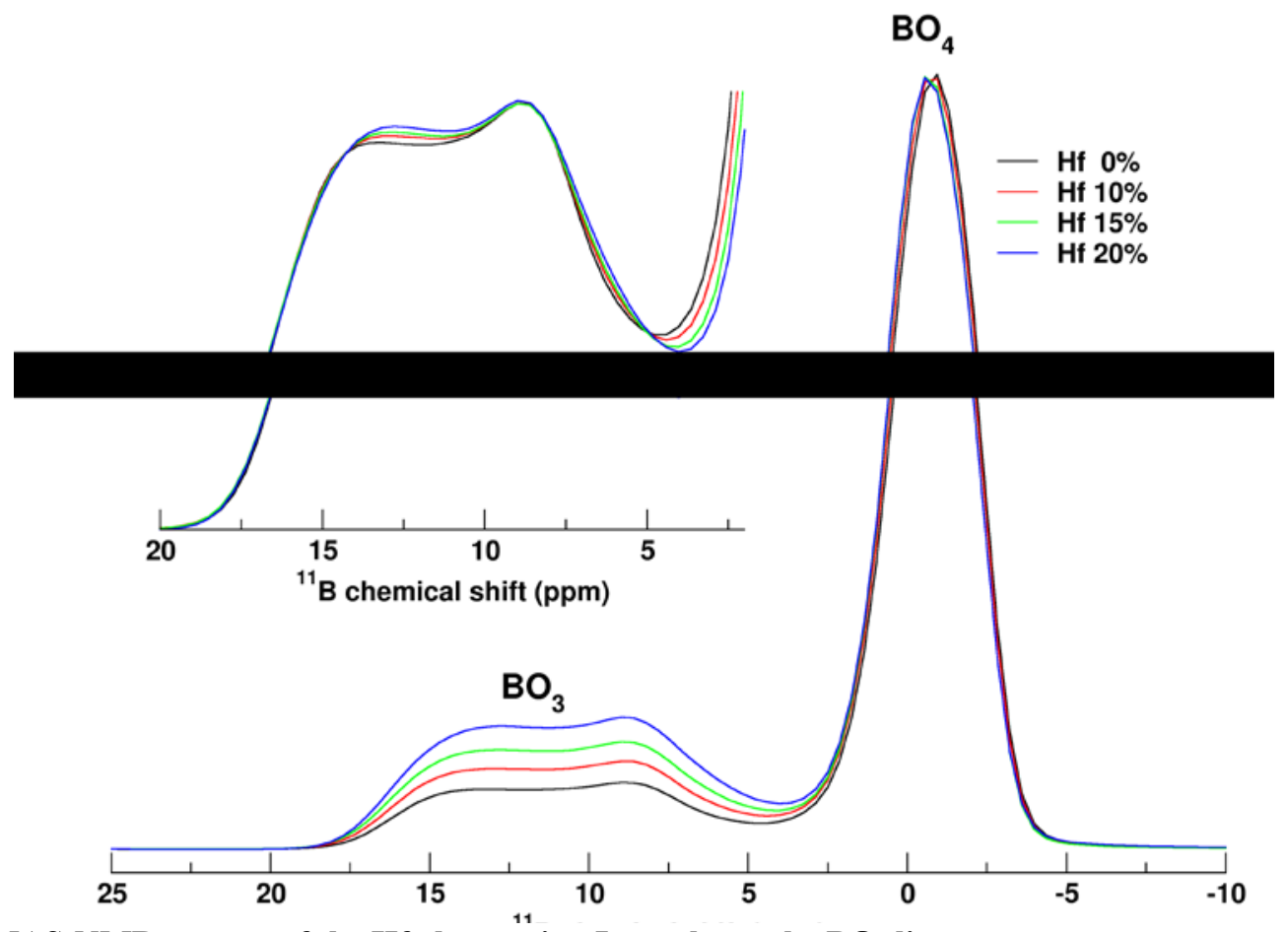

925

926

Fig. $5{ }^{11} \mathrm{~B}$ MAS-NMR spectra of the Hf glass series. Inset shows the $\mathrm{BO}_{3}$ line. 

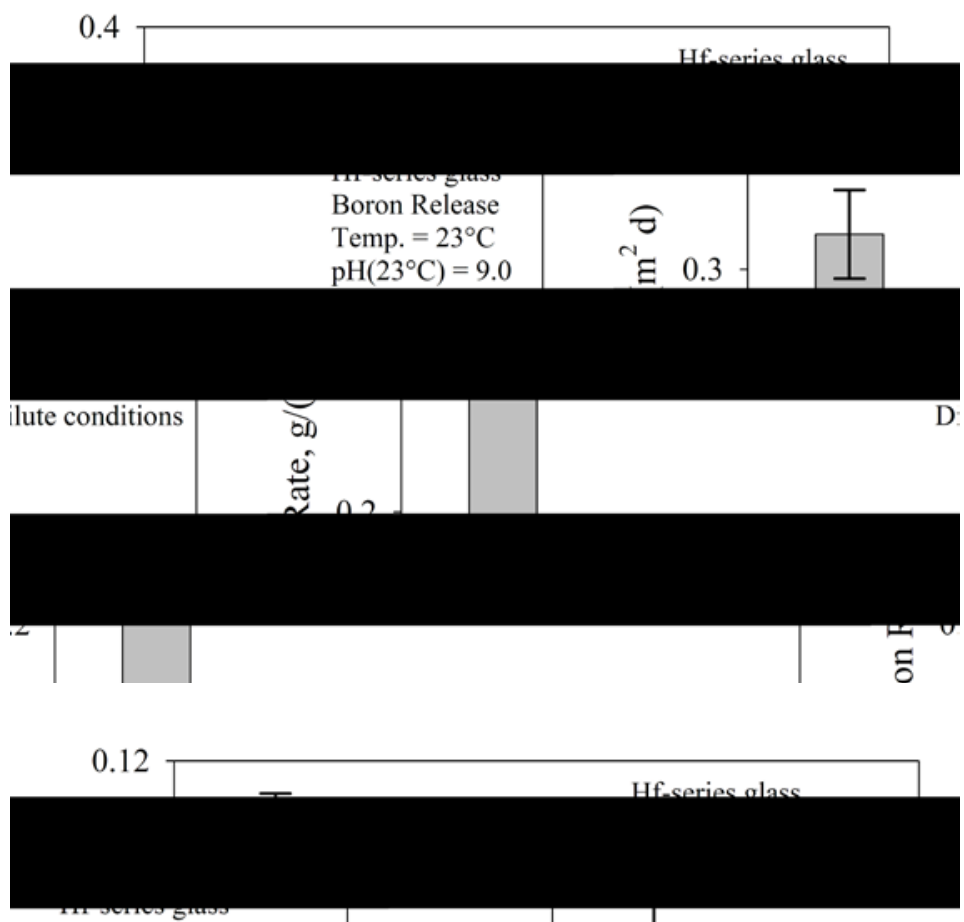

Boron Release

Temp. $=23^{\circ} \mathrm{C}$

$\mathrm{pH}\left(23^{\circ} \mathrm{C}\right)=8.0$
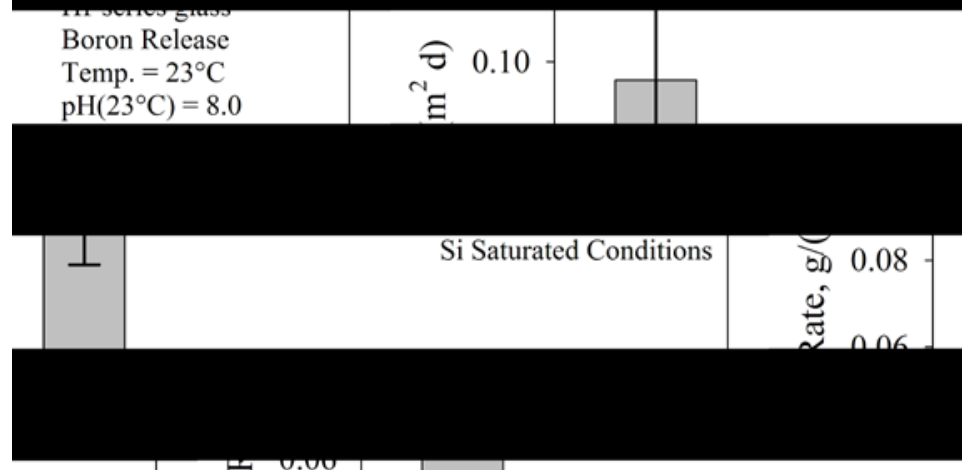

928

929

930

931

932
ธี

Fig. 6 Dissolution Rate, in $\mathrm{g} /\left(\mathrm{m}^{2} \mathrm{~d}\right)$, for $\mathrm{B}$ as a function of $\mathrm{mol} \% \mathrm{HfO}_{2}$ in glass for experiments conducted under diluted conditions and $\mathrm{pH}\left(23^{\circ} \mathrm{C}\right)=9.0$ (top) and near-saturated conditions at $\mathrm{pH}\left(23^{\circ} \mathrm{C}\right)=8.0(\mathrm{bottom})$. The rate measured for the $\mathrm{HF}-5$ sample $\left(20 \mathrm{~mol} \% \mathrm{HfO}_{2}\right)$ under near saturated conditions represents a maximum value. 


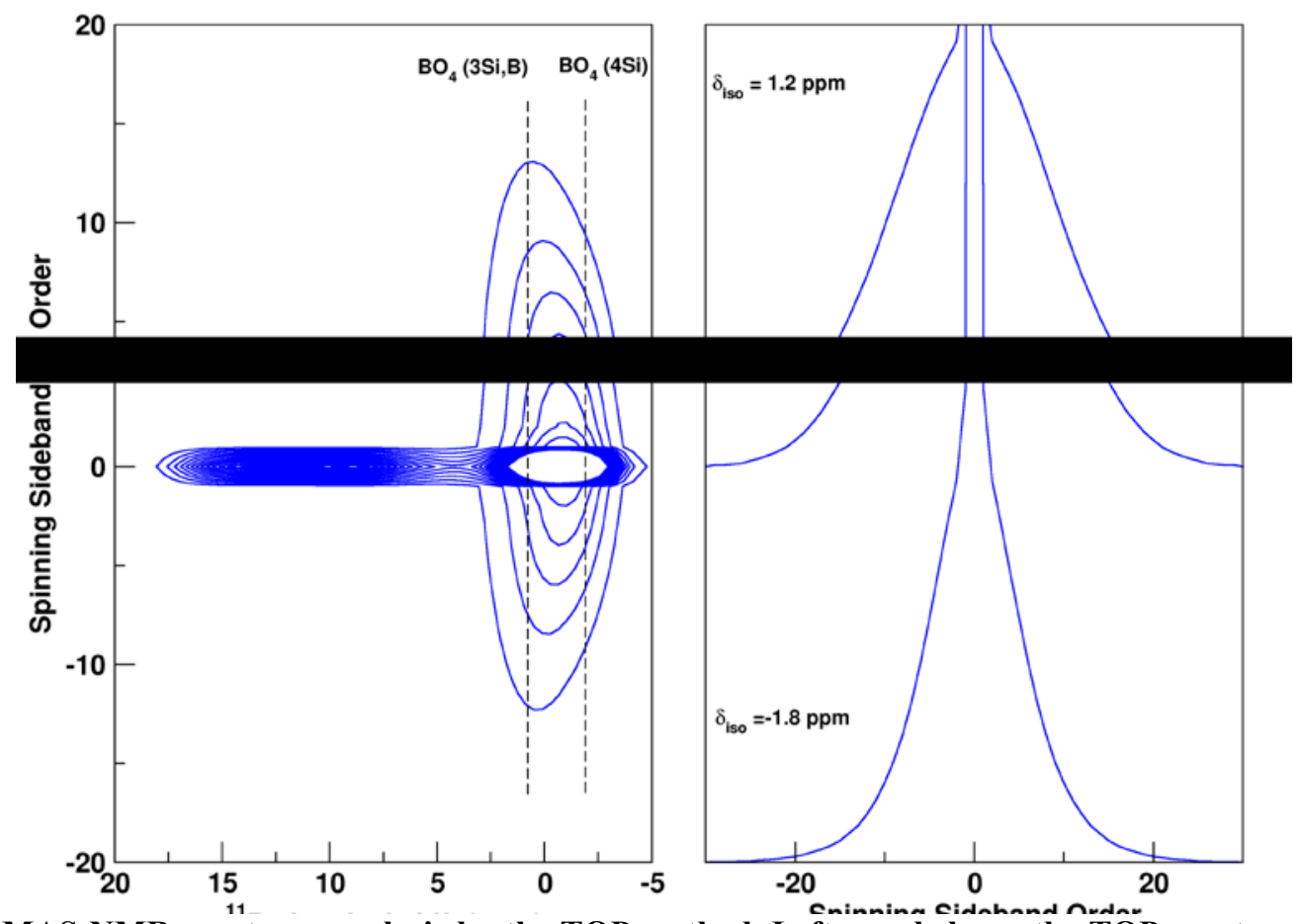

Fig. $7{ }^{11}$ B MAS-NMR spectrum analysis by the TOP method. Left panel shows the TOP spectrum and right panel shows two columns extracted at two chemical shifts (spectra are normalized to the same spinning sideband manifold maximum height).

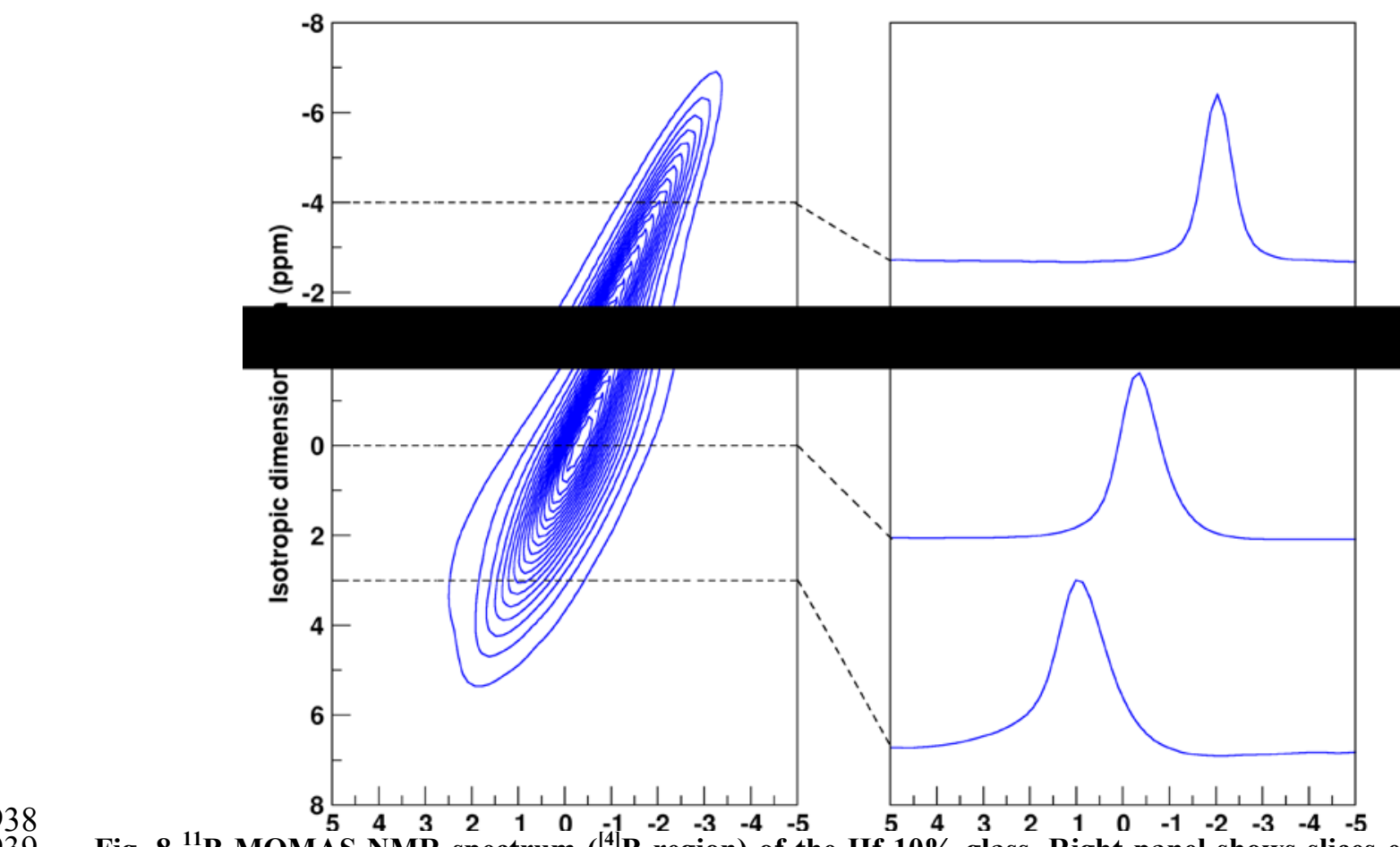

Fig. $8{ }^{11}$ B MQMAS-NMR spectrum $\left({ }^{(4)} \mathrm{B}\right.$ region) of the $\mathrm{Hf} 10 \%$ glass. Right panel shows slices extracted at isotropic shifts (isotropic dimension) $-4,0$ and 3 ppm. 


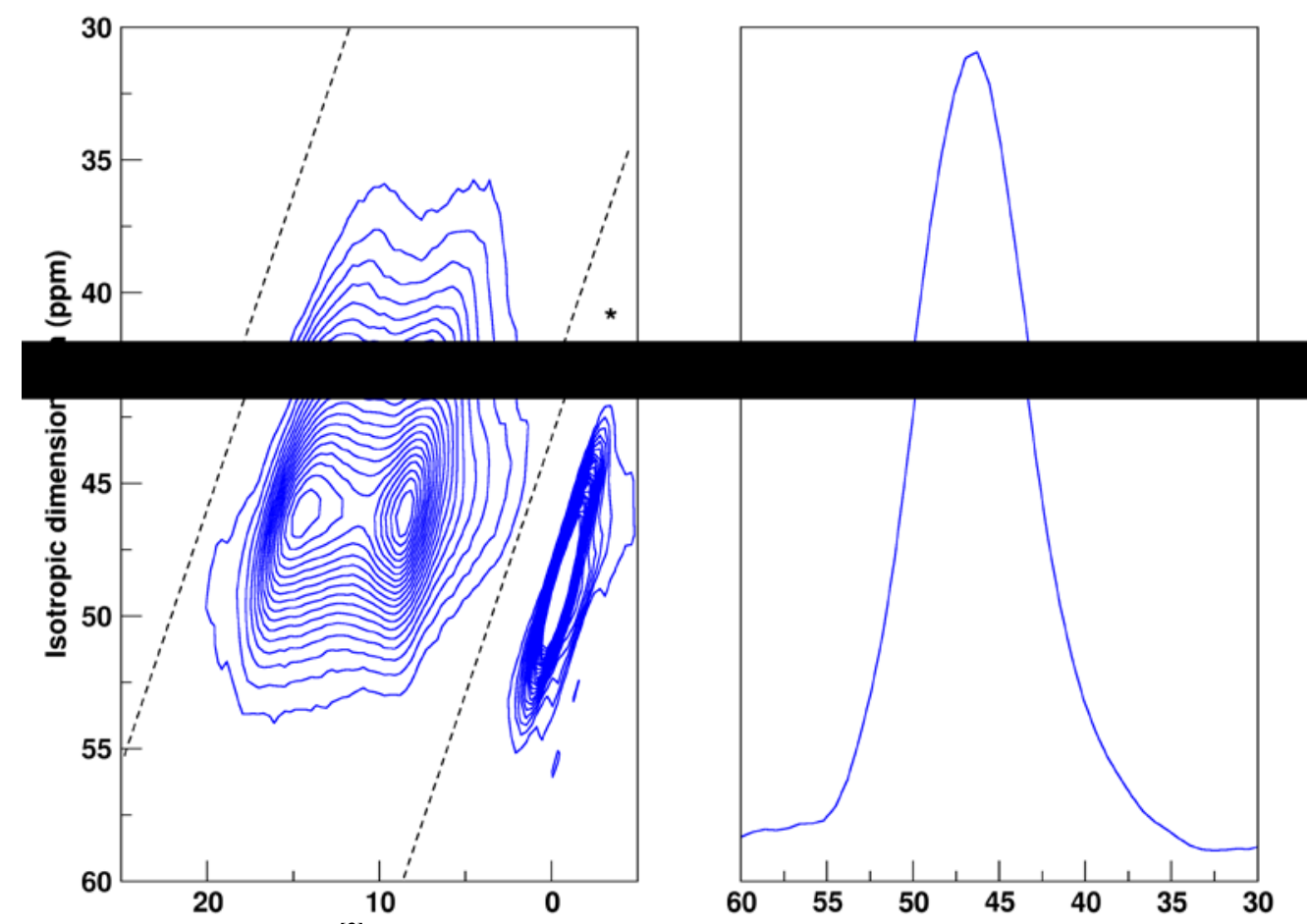

Fig. $9{ }^{11} B$ MQMAS spectrum $\left({ }^{[3]} B\right.$ region) and its projection (of the regions between dashed line) on the isotropic dimension.

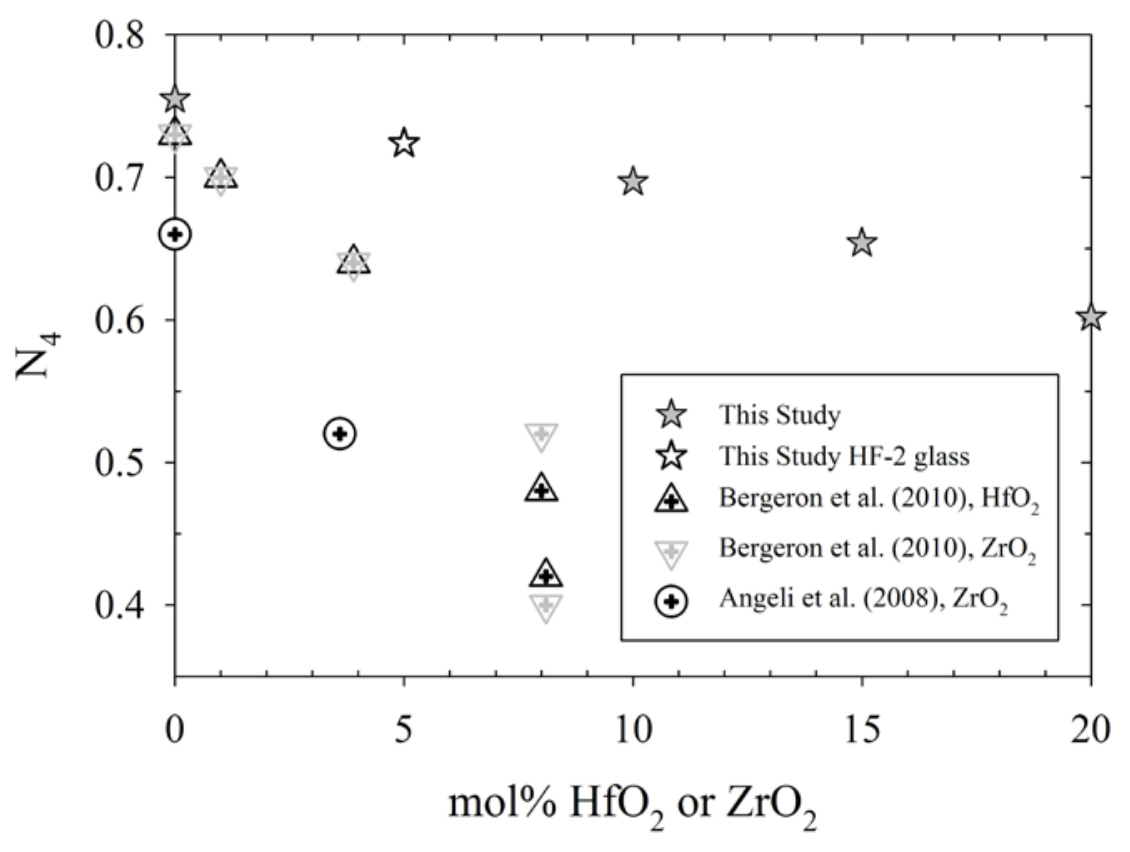

Fig. 10 Comparison of the $\mathrm{N}_{4}$ fraction (ratio of ${ }^{[4]} \mathrm{B}$ to total $\mathrm{B}$ ) as a function of $\mathrm{mol} \% \mathrm{MO}_{2}$ (where $\mathrm{M}=\mathrm{Hf}$ or Zr) for the HF series glasses used in this study and the Hf-bearing glasses tested by Bergeron et al. (2010). Also shown for comparison are the results collected on Zr-bearing glasses by Bergeron et al. (2010) and Angeli et al. (2008). Note: For the $\mathrm{HF}-2$ glass, the $\mathrm{N}_{4}$ fraction was estimated by conducting a linear regression using the results collected for HF-1 through HF-5. 


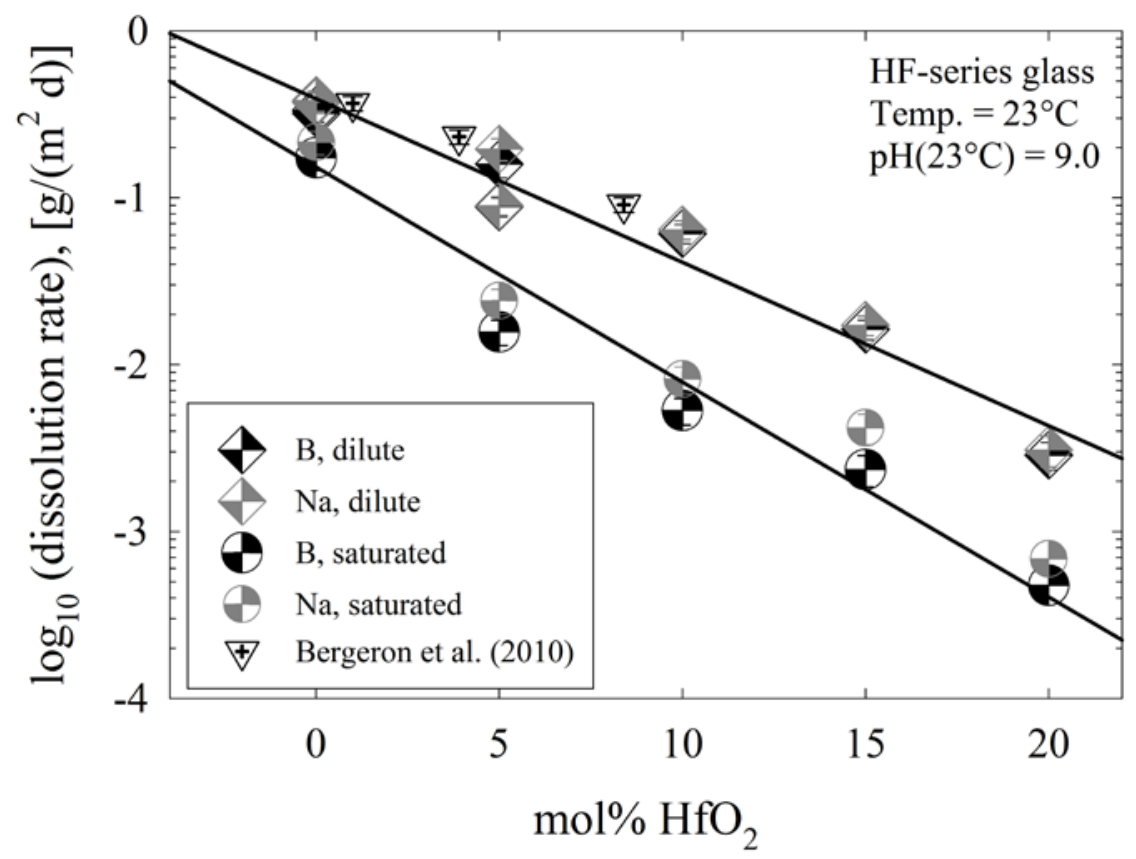

953

954

955

956

Fig. $11 \log _{10}$ (Dissolution Rate), in $\mathrm{g} /\left(\mathrm{m}^{2} \mathrm{~d}\right)$, for $\mathrm{B}$ and $\mathrm{Na}$ as a function of $\mathrm{mol} \% \mathrm{HfO}_{2}$ in glass for experiments conducted under diluted and near-saturated conditions. The $\mathrm{B}$ and $\mathrm{Na}$ values for $20 \mathrm{~mol} \% \mathrm{HfO}_{2}$ represents a maximum value, the actual rates are much lower.
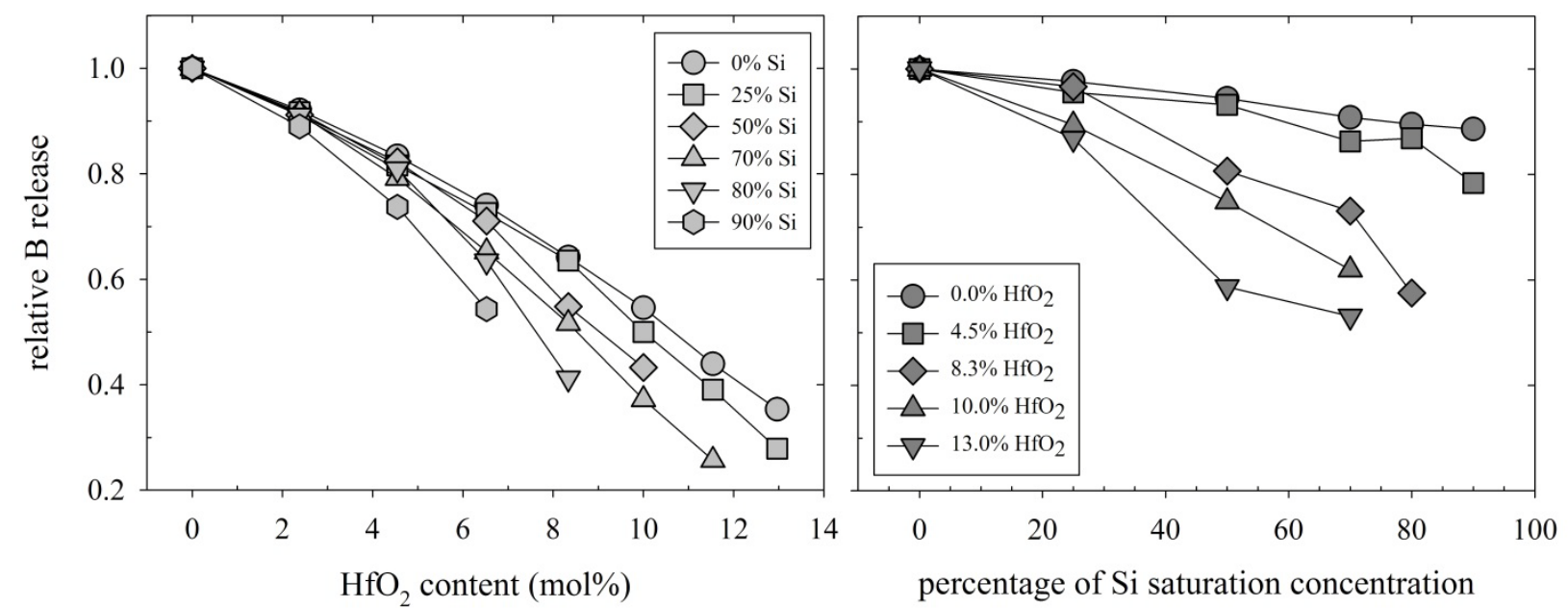

Fig. 12 Results of the Monte Carlo simulation showing (a) $\mathrm{B}$ release rates as a function of $\mathrm{HfO}_{2}$ content relative to that at $\mathrm{O} \mathrm{HfO}_{2}$ mole percent for a range of $\mathrm{Si}$ concentrations in the influent expressed as percentages of the Si saturation concentration; and (b) $\mathrm{B}$ release rates as a function of the Si influent concentration relative to that obtained in dilute conditions for a range of $\mathrm{HfO}_{2}$ contents. 


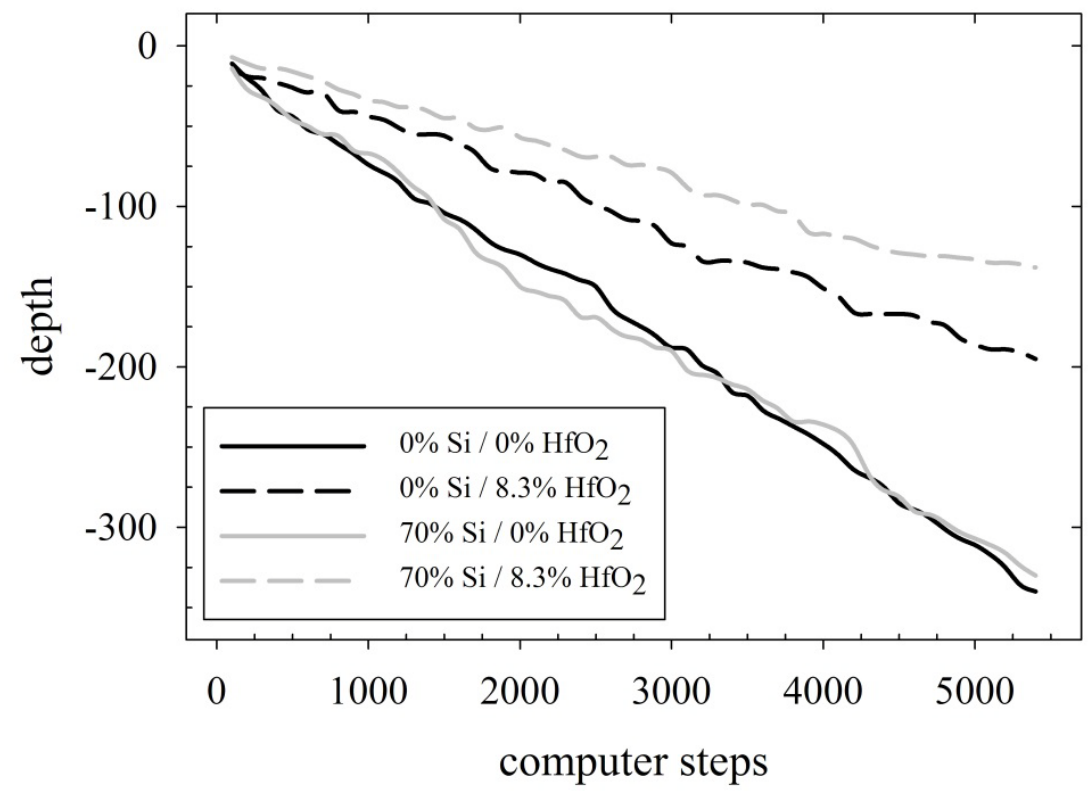

Fig. 13 Results of the Monte Carlo simulation showing the deepest glass layers reached by the aqueous solution (where zero depth corresponds to the initial glass surface) as a function of computer steps for two $\mathrm{HfO}_{2}$ contents in dilute conditions and at $70 \%$ of the Si saturation concentration. 


\section{TABLES}

Table 1. Target chemical compositions (weight \%) of hafnium formulation (HF) glass series specimens.

Table 2. Chemical compositions (mol\%), $\mathrm{Hf} / \mathrm{Si}, \mathrm{Si} / \mathrm{Al}, \mathrm{B} / \mathrm{Al}, \mathrm{B} / \mathrm{Si}$, and select $\Delta \mathrm{H}_{\mathrm{f}}$ values for the hafnium

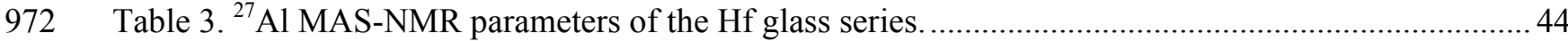

973 Table 4. ${ }^{23} \mathrm{Na}$ NMR parameters of the Hf glass series. ......................................................................4

974 Table 5. Single-pass flow-through experimental conditions and dissolution rates for HF-glass series and

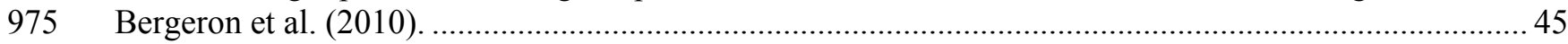

976 Table $6 .{ }^{11} \mathrm{~B}$ NMR parameters used to decompose the MAS-NMR spectra............................................... 46

977 Table 7. Quantification of the boron sites as obtained from the fit of the ${ }^{11}$ B MAS-NMR spectra 46

978

979

980

981

982

983

984

985

986

Table 1. Target chemical compositions (weight \%) of hafnium formulation (HF) glass series specimens.

\begin{tabular}{|c|c|c|c|c|c|}
\hline \multirow[b]{2}{*}{ Oxide } & \multicolumn{5}{|c|}{ Sample ID } \\
\hline & $\mathrm{HF}-1$ & $\mathrm{HF}-2$ & HF-3 & HF-4 & HF-5 \\
\hline $\mathrm{Al}_{2} \mathrm{O}_{3}$ & 8.0 & 6.8 & 5.8 & 5.0 & 4.4 \\
\hline $\mathrm{B}_{2} \mathrm{O}_{3}$ & 16.3 & 13.9 & 12.0 & 10.3 & 9.0 \\
\hline $\mathrm{HfO}_{2}$ & - & 14.8 & 26.8 & 36.7 & 45.1 \\
\hline $\mathrm{Na}_{2} \mathrm{O}$ & 19.4 & 16.5 & 14.2 & 12.3 & 10.6 \\
\hline $\mathrm{SiO}_{2}$ & 56.3 & 48.0 & 41.2 & 35.7 & 30.9 \\
\hline Total & $100.0 \%$ & $100.0 \%$ & $100.0 \%$ & $100.0 \%$ & $100.0 \%$ \\
\hline
\end{tabular}

Table 2. Chemical compositions (mol\%), $\mathrm{Hf} / \mathrm{Si}, \mathrm{Si} / \mathrm{Al}, \mathrm{B} / \mathrm{Al}, \mathrm{B} / \mathrm{Si}$, and select $\Delta \mathrm{H}_{\mathrm{f}}$ values for the hafnium formulation (HF) glass series specimens.

\begin{tabular}{|c|c|c|c|c|c|}
\hline \multirow[b]{2}{*}{ Oxide/Ratio } & \multicolumn{5}{|c|}{ Sample ID } \\
\hline & HF-1 & HF-2 & HF-3 & $\mathrm{HF}-4$ & HF-5 \\
\hline $\mathrm{Al}_{2} \mathrm{O}_{3}$ & 5.02 & 4.76 & 4.50 & 4.25 & 4.00 \\
\hline $\mathrm{B}_{2} \mathrm{O}_{3}$ & 14.98 & 14.24 & 13.50 & 12.75 & 12.00 \\
\hline $\mathrm{HfO}_{2}$ & 0.00 & 5.02 & 10.00 & 15.00 & 20.00 \\
\hline $\mathrm{Na}_{2} \mathrm{O}$ & 20.03 & 18.99 & 18.00 & 17.00 & 16.00 \\
\hline $\mathrm{SiO}_{2}$ & 59.97 & 56.99 & 54.00 & 51.00 & 48.00 \\
\hline Total & 1.00 & 1.00 & 1.00 & 1.00 & 1.00 \\
\hline $\mathrm{Hf} / \mathrm{Si}$ & 0.0 & 0.09 & 0.19 & 0.29 & 0.42 \\
\hline $\mathrm{Si} / \mathrm{Al}$ & 5.97 & 5.99 & 6.00 & 6.00 & 6.00 \\
\hline $\mathrm{B} / \mathrm{Al}$ & 2.98 & 2.99 & 3.00 & 3.0 & 3.00 \\
\hline $\mathrm{B} / \mathrm{Si}$ & 0.50 & 0.50 & 0.50 & 0.50 & 0.50 \\
\hline${ }^{*} \Delta H_{c}$ & & -42.4 & -44.5 & & \\
\hline$\Delta \Pi_{\mathrm{f}}$ & 5 & \pm 0.7 & \pm 0.7 & & 5 \\
\hline
\end{tabular}


987 Table 3. ${ }^{27} \mathrm{Al}$ MAS-NMR parameters of the Hf glass series.

\begin{tabular}{|c|c|c|c|c|}
\hline \multirow{2}{*}{ Glass } & \multicolumn{2}{|c|}{$\delta_{\text {iso }}(\mathrm{ppm})$} & \multicolumn{2}{|c|}{$\mathrm{C}_{\mathrm{Q}}(\mathrm{MHz})$} \\
\hline & mean & Std. Dev. & mean & Std. Dev \\
\hline HF-1 & 61.2 & 4.4 & 4.0 & 1.3 \\
\hline HF-3 & 62.0 & 4.3 & 4.3 & 1.4 \\
\hline $\mathrm{HF}-3^{(\mathrm{a})}$ & 61.3 & 4.4 & 4.3 & 1.4 \\
\hline $\mathrm{HF}-4$ & 62.1 & 4.4 & 4.1 & 1.4 \\
\hline HF-5 & 62.2 & 4.4 & 4.2 & 1.2 \\
\hline \multicolumn{5}{|c|}{$\begin{array}{l}\delta_{\text {iso }}-\text { isotropic chemical shift } \\
C_{\mathrm{Q}}-\text { quadrupolar coupling constant } \\
\left.\eta_{\mathrm{Q}}-\text { quadrupolar asymmetry parameter (constant value of } 0.6\right) \\
\text { (a) from MQMAS, } \\
\text { Lorentzian broadening } \lambda=0.5-0.7 \mathrm{ppm} \text { for all glasses. }\end{array}$} \\
\hline
\end{tabular}

988

989

990

991

992

Table 4. ${ }^{23} \mathrm{Na}$ NMR parameters of the Hf glass series.

\begin{tabular}{|l|ll|ll|}
\hline \multirow{2}{*}{ Glass } & $\delta_{\text {iso }}(\mathrm{ppm})$ & \multicolumn{2}{l|}{$\mathrm{C}_{\mathrm{Q}}(\mathrm{MHz})$} \\
\cline { 2 - 5 } & mean & Std. Dev. & mean & Std. Dev. \\
\hline HF-1 & -3.4 & 7.8 & 2.9 & 0.9 \\
HF-3 & -4.6 & 7.8 & 2.7 & 0.9 \\
HF-4 & -5.3 & 7.5 & 2.6 & 0.9 \\
HF-5 & -6.0 & 7.5 & 2.5 & 0.8 \\
\hline \hline & $\delta_{\text {iso }}$ - isotropic chemical shift \\
$C_{\mathrm{Q}}-$ quadrupolar coupling constant \\
$\eta_{\mathrm{Q}}-$ quadrupolar asymmetry parameter (constant value of 0.6$)$
\end{tabular}




\begin{tabular}{|c|c|c|c|c|c|c|c|c|c|c|}
\hline Sample & \begin{tabular}{|l} 
\\
$\left({ }^{\circ} \mathrm{C}\right)$
\end{tabular} & $\begin{array}{l}\mathbf{p H} \\
\left(23^{\circ} \mathrm{C}\right)\end{array}$ & $\begin{array}{l}\text { Flow rate } \\
(\mathrm{mL} / \mathrm{d})\end{array}$ & $\begin{array}{l}{ }^{\mathrm{a}} \mathbf{S A} \\
\left(\mathbf{m}^{2}\right)\end{array}$ & $\begin{array}{l}{ }^{b} \mathbf{q} / \mathbf{S} \\
(\mathrm{m} / \mathrm{s})\end{array}$ & $\begin{array}{l}\mathrm{C}_{\mathrm{B}} \\
(\mathrm{mg} / \mathrm{L})\end{array}$ & $\begin{array}{l}\mathrm{C}_{\mathrm{Na}} \\
(\mathrm{mg} / \mathrm{L})\end{array}$ & $\begin{array}{l}\mathrm{C}_{\mathrm{Si}} \\
(\mathrm{mg} / \mathrm{L})\end{array}$ & $\begin{array}{l}\text { Rate B } \\
{\left[\mathbf{g} /\left(\mathrm{m}^{2} \mathbf{d}\right)\right]}\end{array}$ & $\begin{array}{l}\text { Rate Na } \\
{\left[g /\left(m^{2} \mathbf{d}\right)\right]}\end{array}$ \\
\hline \multicolumn{11}{|c|}{ near-saturated conditions } \\
\hline $\mathrm{HF}-1 \mathrm{~S}$ & 23 & 8 & 2.0 & $1.21 \times 10^{-3}$ & $1.92( \pm 0.27) \times 10^{-8}$ & 2.67 & 9.33 & 88.59 & $9.58( \pm 1.68) \times 10^{-2}$ & $1.19( \pm 0.21) \times 10^{-1}$ \\
\hline HF-2S & 23 & 8 & 2.0 & $1.34 \times 10^{-3}$ & $1.73( \pm 0.24) \times 10^{-8}$ & 0.19 & 0.75 & 89.49 & $8.67( \pm 1.62) \times 10^{-3}$ & $1.33( \pm 0.25) \times 10^{-2}$ \\
\hline HF-3S & 23 & 8 & 2.0 & $1.25 \times 10^{-3}$ & $1.86( \pm 0.26) \times 10^{-8}$ & 0.05 & 0.25 & 90.32 & $2.93( \pm 0.58) \times 10^{-3}$ & $4.52( \pm 0.91) \times 10^{-3}$ \\
\hline HF-4S & 23 & 8 & 2.0 & $1.39 \times 10^{-3}$ & $1.67( \pm 0.24) \times 10^{-8}$ & 0.02 & 0.08 & 88.19 & $1.29( \pm 0.30) \times 10^{-3}$ & $2.30( \pm 0.52) \times 10^{-3}$ \\
\hline HF-5S & 23 & 8 & 2.0 & $1.21 \times 10^{-3}$ & $1.79( \pm 0.24) \times 10^{-8}$ & 0.0045 & 0.0206 & 90.09 & $<2.62 \times 10^{-4}$ & $<3.78 \times 10^{-4}$ \\
\hline HF-1S & 23 & 9 & 19.25 & $2.58 \times 10^{-4}$ & $8.66( \pm 1.16) \times 10^{-7}$ & 0.22 & 0.79 & 88.37 & $3.07( \pm 0.32) \times 10^{-1}$ & $4.11( \pm 0.56) \times 10^{-1}$ \\
\hline HF-1S & 23 & 9 & 19.22 & $2.36 \times 10^{-4}$ & $9.45( \pm 1.16) \times 10^{-7}$ & 0.18 & 0.70 & 87.54 & $2.92( \pm 0.44) \times 10^{-1}$ & $3.97( \pm 0.55) \times 10^{-1}$ \\
\hline \multicolumn{11}{|c|}{ pH corrected (near-saturated conditions) } \\
\hline HF-1S & 23 & 9 & - & - & - & |- & $\mid$ & - & $1.70( \pm 0.30) \times 10^{-1}$ & $2.10( \pm 0.37) \times 10^{-1}$ \\
\hline HF-2S & 23 & 9 & - & - & - & - & - & - & $1.54( \pm 0.29) \times 10^{-2}$ & $2.36( \pm 0.44) \times 10^{-2}$ \\
\hline $\mathrm{HF}-3 \mathrm{~S}$ & 23 & 9 & - & - & - & - & - & - & $5.18( \pm 1.03) \times 10^{-3}$ & $8.01( \pm 1.60) \times 10^{-3}$ \\
\hline HF-4S & 23 & 9 & - & - & - & - & - & - & $2.29( \pm 0.54) \times 10^{-3}$ & $4.08( \pm 0.92) \times 10^{-3}$ \\
\hline HF-5S & 23 & 9 & - & - & - & - & - & - & $<4.64 \times 10^{-4}$ & $<6.70 \times 10^{-4}$ \\
\hline \multicolumn{11}{|c|}{\begin{tabular}{|l|} 
diluted conditions \\
\end{tabular}} \\
\hline HF-1D & 23 & 9 & 18.3 & $2.59 \times 10^{-4}$ & $8.21( \pm 1.16) \times 10^{-7}$ & 0.23 & 0.76 & $\mid<1$ & $3.20( \pm 0.47) \times 10^{-1}$ & $3.72( \pm 0.51) \times 10^{-1}$ \\
\hline HF-1D & 23 & 9 & 19.1 & $2.34 \times 10^{-4}$ & $9.44( \pm 1.34) \times 10^{-7}$ & 0.21 & 0.68 & $<1$ & $3.34( \pm 0.49) \times 10^{-1}$ & $3.82( \pm 0.53) \times 10^{-1}$ \\
\hline HF-2D & 23 & 9 & 18.8 & $2.76 \times 10^{-4}$ & $7.88( \pm 1.11) \times 10^{-7}$ & 0.10 & 0.35 & $<1$ & $1.59( \pm 0.28) \times 10^{-1}$ & $1.96( \pm 0.30) \times 10^{-1}$ \\
\hline HF-2D & 23 & 9 & 1.9 & $1.22 \times 10^{-3}$ & $1.82( \pm 0.26) \times 10^{-8}$ & 2.43 & 7.01 & $<1$ & $8.82( \pm 1.12) \times 10^{-2}$ & $8.96( \pm 1.15) \times 10^{-2}$ \\
\hline HF-3D & 23 & 9 & 1.9 & $1.18 \times 10^{-3}$ & $1.90( \pm 0.27) \times 10^{-8}$ & 1.38 & 4.14 & $<1$ & $6.09( \pm 0.78) \times 10^{-2}$ & $6.42( \pm 0.82) \times 10^{-2}$ \\
\hline HF-4D & 23 & 9 & 1.9 & $1.27 \times 10^{-3}$ & $1.72( \pm 0.24) \times 10^{-8}$ & 0.35 & 1.06 & $<1$ & $1.63( \pm 0.22) \times 10^{-2}$ & $1.72( \pm 0.23) \times 10^{-2}$ \\
\hline HF-5D & 23 & 9 & 1.9 & $9.75 \times 10^{-4}$ & $2.20( \pm 0.31) \times 10^{-8}$ & 0.04 & 0.13 & $<1$ & $2.87( \pm 0.54) \times 10^{-3}$ & $3.08( \pm 0.64) \times 10^{-3}$ \\
\hline \multicolumn{11}{|c|}{ Bergeron et al. (2010) - pH corrected, $T$ corrected, surface area corrected } \\
\hline $\mathrm{H} 4 \mathrm{C} 4$ & 23 & 9 & - & $7.14 \times 10^{-2}$ & - & - & $\mid$ & $\mid<1$ & $3.68( \pm 0.37) \times 10^{-1}$ & |- \\
\hline $\mathrm{H} 8 \mathrm{C} 4$ & 23 & 9 & - & $7.14 \times 10^{-2}$ & - & - & - & $<1$ & $2.32( \pm 0.23) \times 10^{-1}$ & - \\
\hline $\mathrm{H} 8 \mathrm{C} 8$ & 23 & 9 & - & $7.14 \times 10^{-2}$ & - & - & - & $<1$ & $9.07( \pm 0.91) \times 10^{-2}$ & - \\
\hline
\end{tabular}


Table 6. ${ }^{11} \mathrm{~B}$ NMR parameters used to decompose the MAS-NMR spectra.

\begin{tabular}{|l|ll|ll|}
\hline \multirow{2}{*}{ Site } & \multicolumn{3}{|l|}{$\delta_{\text {iso }}(\mathrm{ppm})$} & $\mathrm{C}_{\mathrm{Q}}(\mathrm{MHz})$ \\
\cline { 2 - 5 } & mean & Std. Dev. & mean & Std. Dev. \\
\hline $\mathrm{BO}_{4}(3 \mathrm{Si}, 1 \mathrm{~B})$ & 0.1 & 1.1 & 0.6 & 0.2 \\
$\mathrm{BO}_{4}(4 \mathrm{Si}, 0 \mathrm{~B})$ & -1.5 & 1.0 & 0.2 & 0.1 \\
$\mathrm{BO}_{3}(\mathrm{~B})$ & 17.5 & 1.4 & 2.5 & 0.1 \\
$\mathrm{BO}_{3}(\mathrm{Si})$ & 13.7 & 2.4 & 2.7 & 0.1 \\
\hline \hline$\delta_{\text {iso }}-$ isotropic chemical shift & \\
$C_{\mathrm{Q}}-$ quadrupolar coupling constant \\
$\eta_{\mathrm{Q}}-$ quadrupolar asymmetry parameter (constant value of 0.6$)$.
\end{tabular}

996

997

998

999

1000

Table 7. Quantification of the boron sites as obtained from the fit of the ${ }^{11} B$ MAS-NMR spectra

\begin{tabular}{|l|l|l|l|l|l|}
\hline Glass & $\mathrm{BO}_{4}(3 \mathrm{Si}, \mathrm{B})$ & $\mathrm{BO}_{4}(4 \mathrm{Si}, 0 \mathrm{~B})$ & $\mathrm{BO}_{3}(\mathrm{~B})$ & $\mathrm{BO}_{3}(\mathrm{Si})$ & $\mathrm{N}_{4}$ \\
\hline HF-1 & 48.9 & 26.6 & 16.9 & 7.6 & 75.5 \\
HF-2 $^{*}$ & - & - & - & - & 72.4 \\
HF-3 & 47.8 & 21.9 & 21.0 & 9.3 & 69.7 \\
HF-4 & 47.5 & 17.9 & 24.4 & 10.3 & 65.4 \\
HF-5 & 44.0 & 16.2 & 28.1 & 11.8 & 60.2 \\
\hline
\end{tabular}

*Value estimated by performing a linear regression of $\mathrm{N}_{4}$ fraction versus molar fraction $\mathrm{HfO}_{2}$ content for HF-1 through HF-5. Equation of the line $-\mathrm{N}_{4}=-0.752 \times$ molar $\mathrm{HfO}_{2}+0.7616$. 